\title{
AN INDIVIDUAL DIFFERENCES INVESTIGATION OF THE RELATION BETWEEN LIFE EVENT STRESS AND WORKING MEMORY CAPACITY
}

A thesis presented to the faculty of the Graduate School of Western Carolina University in partial fulfillment of the requirements for the degree of Master of Arts in Clinical Psychology

By

\author{
Haley Grace Goller \\ Director: Dr. Matt Meier \\ Assistant Professor of Psychology \\ Department of Psychology
}

Committee Members: Dr. David McCord, Psychology

Dr. David de Jong, Psychology

April 2019 


\section{TABLE OF CONTENTS}

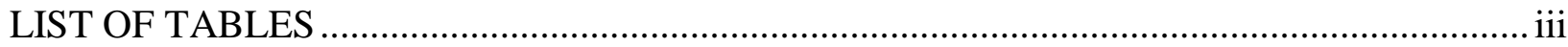

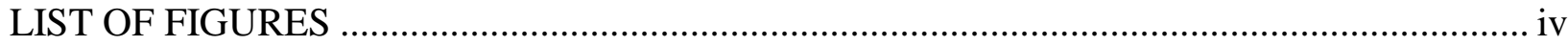

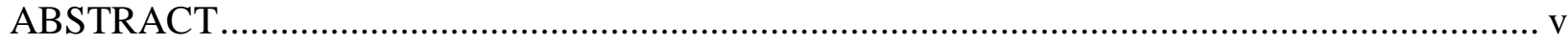

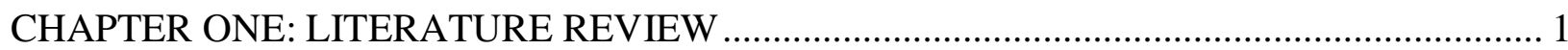

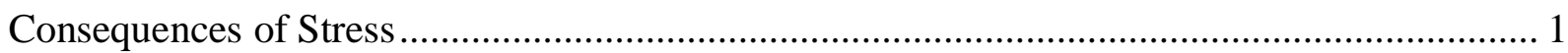

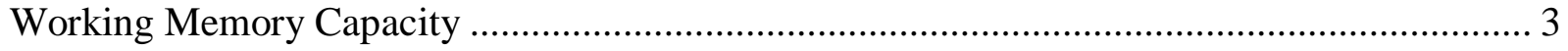

Effects of Stress on Working Memory …………........................................................ 4

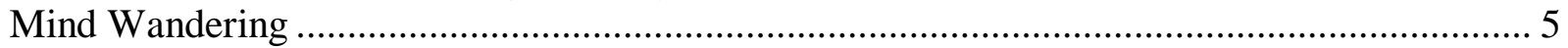

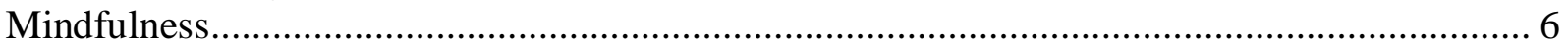

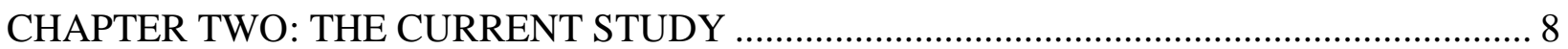

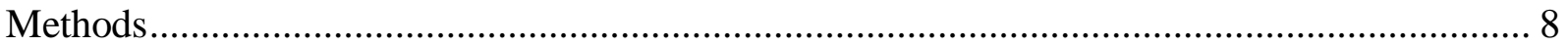

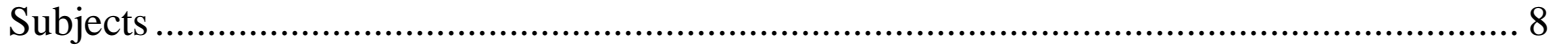

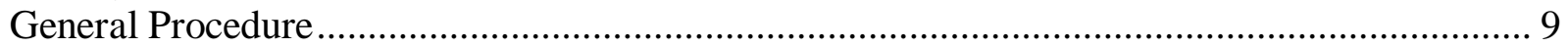

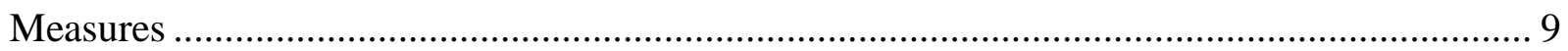

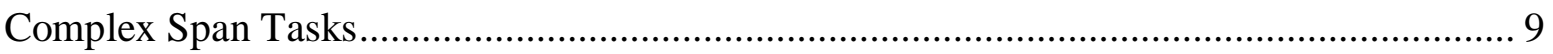

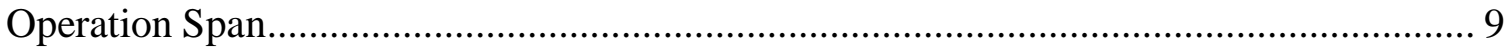

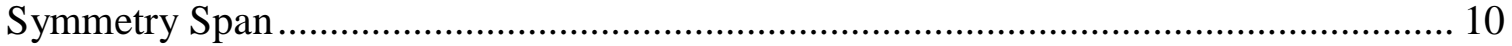

Sustained Attention to Response Task................................................................... 11

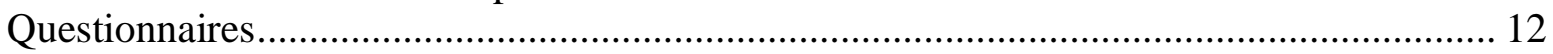

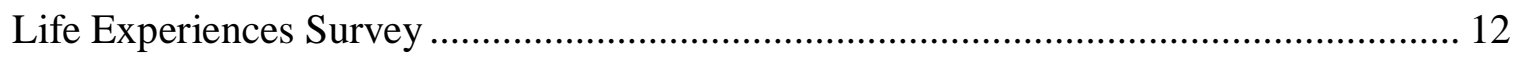

Ruminative Response Scale .................................................................................. 12

Trait level mindfulness ................................................................................................ 13

Five Facet Mindfulness Questionnaire - Short Form .................................................... 13

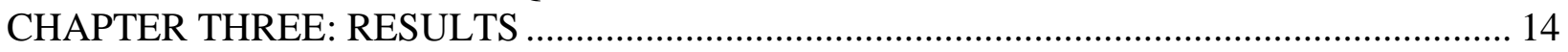

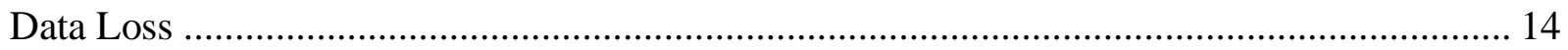

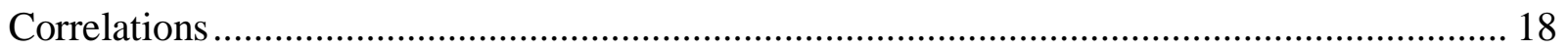

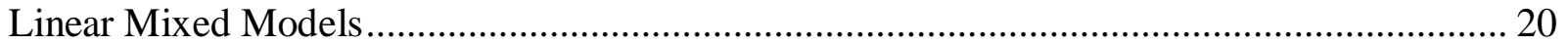

Mediation Analyses …………………………………......................................... 23

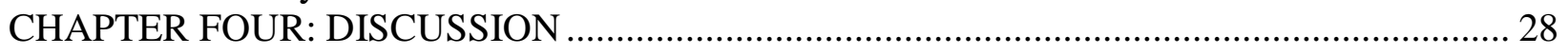

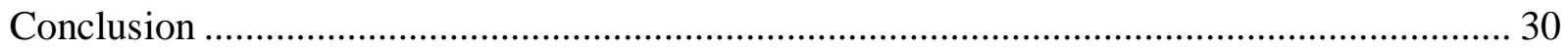

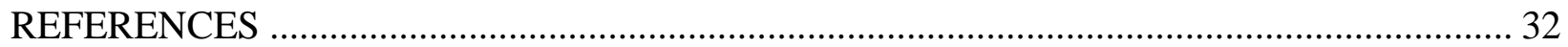

APPENDIX A: OPERATION SPAN (OSPAN) COMPLEX SPAN TASK …………................ 42

APPENDIX B: SYMMETRY COMPLEX SPAN TASK (SYMSPAN) ………….................... 43

APPENDIX C: SEMANTIC SUSTAINED ATTENTION TO RESPONSE TASK (SART) ..... 45

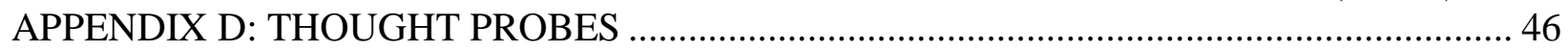

APPENDIX E: LIFE EXPERIENCES SURVEY (LES) …………...................................... 47

APPENDIX F: RUMINATIVE RESPONSE SCALE ………........................................... 51

APPENDIX G: FIVE FACET MINDFULNESS QUESTIONNAIRE - SHORT FORM........... 52 


\section{LIST OF TABLES}

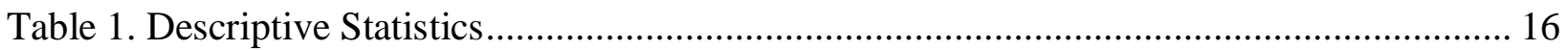

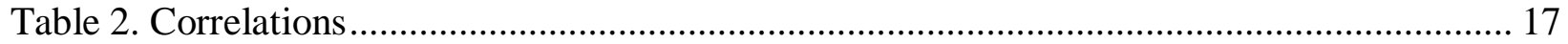

Table 3. Mixed Linear Models - Predictors of Response Time Variability in the SART ........... 21

Table 4. Generalized Mixed Linear Models - Predictors of SART Accuracy ............................. 22

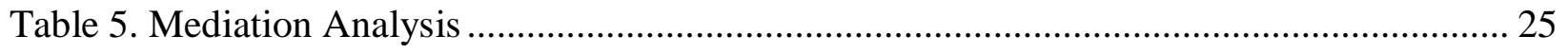




\section{LIST OF FIGURES}

Figure 1. Correlation between total negative life event stress and working memory

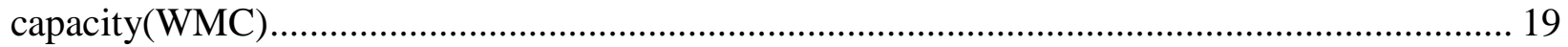

Figure 2. Correlation between total negative life event stress and SART mind wandering ........ 20

Figure 3. Response Time Standard Deviation by Valance Thought Report .............................. 22

Figure 4. Target Accuracy by Valance Thought Report ....................................................... 23

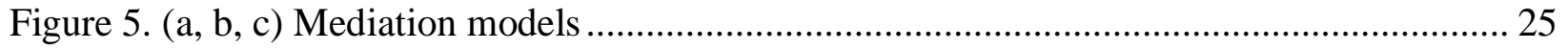

Figure 6. $(\mathrm{a}, \mathrm{b})$ Moderated mediation models ......................................................................... 26 


\begin{abstract}
AN INDIVIDUAL DIFFERENCES INVESTIGATION OF THE RELATION BETWEEN LIFE EVENT STRESS AND WORKING MEMORY CAPACITY
\end{abstract}

Haley Grace Goller, M.A.

Western Carolina University (April, 2019)

Director: Dr. Matt Meier

The effects of stress in both academic and social settings are well established. However, the effects of stress on cognitive functioning are less so. This study explored the relation between life event stress and cognitive functioning; first by attempting to replicate a negative association between life event stress and working memory capacity and then by testing if the propensity to mind wander, the emotional valence of mind wandering, or the tendency to ruminate are potential mechanisms through which life stress can affect working memory capacity. In addition, I tested if trait level mindfulness is a protective factor against the effects of life stress on working memory capacity. Negative life event stress did not correlate with working memory capacity. Mind wandering, the valance of mind wandering, rumination, and trait level mindfulness did not serve as mediators in the relationship between working memory capacity and negative life event stress. When compared to neutral and positively valanced mind wandering, negatively valanced mind wandering was not more harmful to SART reaction time. However, when compared to neutral, but not positively valanced mind wandering, negatively valanced mind wandering was more harmful to SART accuracy. Finally, no evidence was found for trait level mindfulness serving as a protective factor. 


\section{CHAPTER ONE: LITERATURE REVIEW}

Stress is a nonspecific response to a shift in the environment or environmental threat that produces physiological, cognitive, and emotional change (Baum \& Posluszny, 1999). There are a variety of definitions of "stress" used throughout the literature (Cohen, Murphy, \& Prather, 2019) ranging from threatening environmental situations, individual appraisals of threat, and the physiological systems that produce reactions in response to changing situations (Cohen, Gianaros, \& Manuck, 2016). Despite varying definitions, there seems to be a great deal of overlap, and a growing body of evidence supports the threat or harm approach (Cohen et al., 2019) where stress is experienced when events are judged by the individual as being harmful or

threatening. The physical, psychological, and social effects of stressful events have been found to be cumulative (Baum \& Poluszny, 1999; Cohen et al., 2019). For example, individuals with greater life stressors are at an increased risk for cardiac death (Rahe \& Lind, 1971), susceptible to alcohol use and consumption disorders (Keyes et al., 2011), and experience increased levels of anxiety and depression (Sarason et al., 1978).

\section{Consequences of Stress}

Stress has negative effects on physical and psychological well-being (e.g. Baddeley \& Idzikowski, 1985; Banks, Tartar, \& Welhaf, 2014; Baum \& Poluszny, 1999; Cohen et al., 2019; Constantino, Sekula, Ranin, \& Stone, 2000; Keyes, Hatzenbuehler, \& Hasin, 2011; Klein \& Boals, 2011; Rahe \& Lind, 1971; Sarason, Johnson, \& Seigal, 1978). For example, stress has been associated with outcomes including depression, impaired autoimmune functioning (Constantino et al., 2000), and impaired cognitive functioning (Banks \& Boals, 2016; Hyun, Sliwinski, \& Smith, 2018; Klein \& Boals, 2001; Sliwinski, Smyth, Hofer, \& Stawski, 2006). 
Klein and Boals (2001) provided evidence that subjects who have experienced more negative stressful life events had lower working memory capacity. Klein and Boals (2001) found that increases in negative life event stress (increased reports of events that were negative and impactful on the Life Experiences Scale; LES) were negatively correlated with differences in overall working memory capacity $(r=-.46, p<.01)$. Life event stress refers to any significant life change, positive or negative, such as the recent death of a loved one or a new marriage (Sarason et al., 1978). These results are consistent with the findings of Sarason et al. (1978), who found that only the events that were perceived as negative were related to negative outcomes such as depression and anxiety. Klein and Boal's (2001) claim is that cumulative (versus proximal or in-the-moment) life stress impairs working memory capacity. This influential finding has been cited 294 times (89 times since 2015).

Experiencing stressful life events alone does not predict negative outcomes; stressors must be rated by the individual as being both negative and highly impactful to be associated with negative outcomes (Sarason et al., 1978). For example, women who have experienced higher levels of negative life experiences, such as abuse, show increased levels of depression and decreased immune functioning compared to those who reported stressors that were not "negative" (Constantino et al., 2000). Moreover, life event stress (indicated by self-reported life changes) has been correlated with negative physical and psychological outcomes such as depression, anxiety, and decreased academic performance (Sarason et al., 1978; Cohen et al., 2019). Life event stress has also been linked to poorer performance on a sentence verification task, but not to an explicit or implicit memory task (Yee, Edmondson, Santoro, Begg, \& Hunter, 1996), suggesting that life event stress negatively impacts active information processing carried out by the working memory system (Klein \& Boals, 2001). For example, life event stress has 
been associated with differences in problem solving ability and information processing (Klein \& Boals, 2001) as well as poorer performance on analogical reasoning tasks (Klein \& Barnes, 1994).

Although the relationship found by Klein and Boals (2001) between negative life event stress and working memory capacity has not been successfully replicated, the relation between acute (in-the-moment) stress and working memory impairments has been found multiple times (Banks \& Boals, 2016; Sliwinski et al., 2006) and in various domains including perceptual-motor performance (Baddley \& Idzikowski, 1985), memory (Kuhlmann, Piel, \& Wolf, 2005), sustained attention (Banks et al., 2014), and working memory (Banks, Tartar, \& Tamayo, 2015). Despite the evidence supporting the negative relationship between (acute) stress and working memory, various studies have failed to support a direct relationship between negative life event stress and working memory deficits (Banks, 2011; Banks \& Boals, 2016; Lewis, Nikolova, Chang, \& Weekes, 2008)

\section{Working Memory Capacity}

Working memory is a complex cognitive system that maintains and manipulates information, as well as controls attention (Engle, 2002). To perform well on tasks designed to measure working memory, individuals must focus their attention on the task while simultaneously ignoring off-task demands/thoughts (Stolzfus, Hasher \& Zacks., 1996). People differ in the efficiency with which they can use this system. Individuals with a higher working memory capacity are better at maintaining information in the face of distractions than lower working memory capacity people (Randall, Oswald, \& Beier, 2014). An individual's working memory capacity predicts success on consequential real-life outcomes such as reading comprehension (Daneman \& Carpenter, 1980), and multitasking (Hambrick, Oswald, Darowski, 
Rench, \& Brou, 2010). Additionally, individuals with lower working memory capacity perform worse on low-level attention tasks, such as the Stroop task (Kane \& Engle, 2003; Meier \& Kane, 2013).

\section{Effects of Stress on Working Memory}

Stress can affect working memory. Schoofs et al. (2008) exposed subjects to psychosocial stress via the Trier Social Stress Test, a test designed to induce stress in laboratory settings by asking subjects to give a speech and solve simple math problems in front of a panel of "judges." Following this manipulation, individuals completed a working memory task (numerical $n$-back task with single digits). The $n$-back task presents subjects with a series of single digit numbers and requires that the subject indicate when the current stimulus is the same as the one they saw $n$ trials previously. When compared to a control condition, individuals in the stress condition had higher levels of cortisol and impaired performance on the numerical $n$-back.

The effects of stress on working memory capacity have real-world implications. For example, Kleider et al. (2010) found that police officers with a lower working memory capacity were more likely to make shooting errors (shooting unarmed targets/failure to shoot armed targets on a simulated shooting task) than those with a higher working memory capacity. This relation was only present when the officers were exposed to a negatively arousing or threatening scenario prior to engaging in the shooting task. Based on the negative correlation between negative life event stress and working memory capacity, Klein and Boals (2001) speculated that the observable differences in overall working memory capacity between individuals might, in part, be linked to psychosocial factors, such as stressful life events, and that people who experience these life events have an increased number of unwanted thoughts. These unwanted 
thoughts compete with the current task for cognitive resources, thus resulting in impaired functioning on the task.

\section{Mind Wandering}

Mind wandering refers to thinking about something other than the current task (task unrelated thoughts). One potential mechanism though which stress may impair working memory functioning is by increasing instances or changing the qualities of mind wandering (Banks \& Boals, 2016). For example, adolescents who have experienced childhood maltreatment engage in less positively valanced mind wandering when compared those who did not experience maltreatment (Hoffmann et al., 2018). The negative association between mind wandering and task performance has been demonstrated in a variety of situations including reading comprehension tasks (McVay \& Kane, 2012; Smallwood, McSpadden, \& Schooler, 2008), and working memory tasks (Banks \& Boals, 2016; Banks, Tartar, \& Tamayo, 2015). Greater levels of mind wandering have also been associated with increases in car accidents (Knowles \& Tay, 2002) and poorer academic performance (Kane et al., 2017; Wammes, Seli, Cheyne, Boucher, \& Smilek, 2016). Banks and Boals (2016) have provided preliminary evidence that negative life events impact working memory capacity by increasing mind wandering, which mediates the relationship between life event stress and working memory impairments.

Although mind wandering has been shown to negatively impact cognitive task performance (Randall, Oswald, \& Beier, 2014), some evidence suggests that specific characteristics of the mind wandering episode have differential impacts (Banks, Welhaf, Hood, Boals, \& Tartar, 2016). Banks et al. (2016) examined the effect of emotional valance on the relations among mind wandering, working memory, and sustained attention. They did this by asking subjects at random intervals during a working memory or sustained attention task if they 
were thinking thoughts unrelated to the task (task unrelated thoughts; TUTs). TUTs, here, are the operationalization of mind wandering. When subjects indicated that they were off-task, they were asked to indicate if the content of the TUT was positive, negative, or neutral. Only negatively-valenced TUTs were related to impaired performance on both the working memory and sustained attention tasks (Banks et al., 2016). It seems reasonable that experiencing stress related to negative life events may increase the proportion of negatively-valenced TUTs and thus impair working memory performance.

Everyone engages in mind wandering (Christoff, Gordon, Smallwood, Smith, \& Schooler, 2009; Killingsworth \& Gilbert, 2010, Raichle, MacLeod, Snyder, Powers, Gusnard, \& Shulman, 2001). However, the valence and frequency of mind wandering varies within and amongst people (Killingsworth \& Gilbert, 2010). One extreme form of negative mind wandering is rumination - experiencing frequent, intrusive, negative thoughts (Nolen-Hoeksema, 2000). Rumination is one of the key cognitive vulnerabilities in the maintenance of depressive disorders (Nolen-Hoeksema, Wisco, \& Lyubomirskym, 2008) and has been associated with several negative outcomes including cognitive deficits (Marchetti, Koster, Klinger \& Alloy, 2016), and working memory impairments (Joormann, Levens, \& Gotlib, 2011). Rumination predicts the severity and duration of depressive symptoms as well as symptoms of anxiety (Nolen-Hoeksema, 2000). Research has also suggested a relationship between working memory and the maintenance of rumination, where working memory deficits underlie ruminative responses (Hoffmann et al., 2016; Joorman \& Gotlin, 2008).

\section{Mindfulness}

Mindfulness is an integral component when attempting to understand the negative effects of stress on working memory (Chambers, Lo, \& Allen, 2008; Mrazek, Franklin, Phillips, Baird, 
\& Schooler, 2013; Zeidan, Johnson, Diamond, David, \& Goolkasian, 2010). The goal of mindfulness is present-moment awareness that is free from worry about the past or future (Kabat-Zinn, 1994). A second integral component of mindfulness is maintaining this awareness without attempting to suppress thoughts or emotionally react to stimuli (Kabat-Zinn, 1994). Mindfulness training is used to help individuals develop trait-level mindful tendencies (Jha, Stanley, Kiyonaga, Wong, \& Gelfand, 2010). Mindfulness training has been shown to improve working memory functioning, limit instances of mind wandering, and increase sustained attention (Chambers el al., 2008; Mrazek et al., 2013; Zeidan et al., 2010). Individuals with higher trait levels of mindfulness are more cognitively flexible and have improved attentional control (Moore \& Malinowski, 2009). In addition to the effects of mindfulness on these cognitive attributes, mindfulness acts as a buffer against the negative effects of stress on working memory (Banks et al., 2015a; Jha, Morrison, Parker \& Stanley, 2016; Leonard et al., 2013;).

Jha et al. (2016) compared working memory capacity between pre-deployment Marines who completed 8 weeks of mindfulness training to those who had not. This 8-week intervention was designed to increase present moment awareness. Measures of working memory capacity were obtained upon enrollment in the study and again approximately 9- weeks later. Results indicated that over the 9-week period, individuals who underwent mindfulness training showed increased working memory performance, despite pre-deployment stress. Those who did not participate in mindfulness training showed impaired working memory performance. 


\section{CHAPTER TWO: THE CURRENT STUDY}

The current study had four main goals: 1) To replicate the correlation between cumulative negative life event stress and working memory capacity; 2) Replicate the findings of Banks et al. (2016) that suggest that negatively valanced mind wandering impairs performance more than positively valanced or neutral mind wandering; 3) Test if negative life stress impairs working memory capacity through the mechanisms of trait level mindfulness, rumination, or mind wandering; 4) Determine if trait level mindfulness protects against effects of life stress on working memory capacity. To this end, I administered two working memory tasks, a measure of sustained attention, a measure of mind wandering, and questionnaires designed to measure life event stress, trait level mindfulness, and rumination to a sample of subjects.

\section{Methods}

\section{Subjects}

A total of 154 undergraduate students at Western Carolina University ( $M$ first-year student composite SAT score = 1055 and 1018 for the cohort entering Fall 2015- Fall 2016, respectively) completed the informed consent for this study. I collected demographic data from 153 of these subjects (data from one subject was lost due to technical error; one student erroneously reported an age of 1 in the demographics, that age was not included in these statistics; one subject did not respond to when asked their age). Of these 153 subjects, $54 \%$ were female (one subject did not respond). Subjects had a mean age of $19(\mathrm{SD}=2)$. Of the subjects who gave ethnicity information (one subject provided two responses), $75 \%$ identified as white, $11 \%$ as black, $5 \%$ as multiracial, $3 \%$ as Asian, $1 \%$ as Native American or Alaskan, and $5 \%$ as other. As compensation for their participation, subjects received partial credit for a course 
requirement. This thesis is part of a larger, ongoing, preregistered study. The larger project was preregistered on September $7^{\text {th }}, 2018$ (https://aspredicted.org/zp2w6.pdf)

\section{General Procedure}

In one 90-minute session, either individually or in groups of two, subjects completed measures in the following order: operation span, symmetry span, Semantic Sustained Attention To Response Task, Five Facet Mindfulness Questionnaire - Short Form Ruminative Response Scale, Life Experiences Survey, and a brief demographics questionnaire. All tasks were administered on computers using E-Prime software (Psychology Software Tools, Pittsburg, PA). Before completing these measures, subjects completed an informed consent. After completing the measures, subjects were debriefed and given an opportunity to ask questions.

\section{Measures}

\section{Complex Span Tasks}

To limit the amount of time for each experimental session and therefore maximize the number of subjects I could test in a semester, I used shortened complex span tasks (Foster et al., 2015). Subjects completed one block each of two complex span tasks (the traditional variants of these tasks use 3 blocks). Using two one-block complex span tasks provides superior measurement properties over using one complete (3 block) span task (Foster et al., 2015).

Operation Span (Unsworth, Heitz, Schrock, \& Engle, 2005; Appendix A). The Operation Span is an automated complex span task designed to measure working memory capacity. Following practice with math problems and remembering letters first individually and then combined, subjects begin the scored task. In the scored task subjects are presented with a math problem to verify. Following the math problem [e.g., (2 . 2) $+1=5$; half were true], subjects 
are presented with a letter to remember from a set of 12 possible letters (3-7 letters per trial, presented for 1 second each). This sequence was repeated three to seven times resulting in five trials (i.e., each set size was presented once). The order of these trials was random. At the end of each trial, subjects are presented with a grid of all 12 possible letters and asked to select the letters in the correct order by clicking on them using a computer mouse. Scores were calculated by adding the total number of letters recalled in the correct serial order (Conway et al., 2005). The maximum score for this task was 25. Chronbach's $\alpha$ for one block of this task is .69 (Foster et al., 2015).

Symmetry Span (Symspan; Unsworth, Redick, Heitz, Broadway, \& Engle, 2009; Appendix B). In this task, subjects were asked to recall a series of red squares presented within a matrix while simultaneously engaging in a symmetry-judgement task. Subjects are first presented with a symmetry-judgement task in which they are shown an $8 \times 8$ black matrix with some of the squares colored black and asked to decide whether or not the image is symmetrical about its vertical axis. This was followed immediately by a $4 \times 4$ matrix with one cell filled in (red) for $650 \mathrm{~ms}$. During the recall phase, subjects indicate the location and sequence of red squares in the previous displays by clicking on the cells in an empty matrix. There was one trial of each set size, ranging from two to five presented in random order. Scores were calculated by obtaining the number of correct items recalled in the correct position. The maximum score for this task was 14. Chronbach's $\alpha$ for one block of this task is .61 (Foster et al., 2015).

I created a working memory composite score by averaging z-scores on both the Symspan and Ospan. Using a composite score for working memory is consistent with evidence indicating that measured differences in working memory performance are largely due to domain-general processes (Kane et al., 2004). 
Sustained Attention to Response Task (SART; Kane et al., 2016; Appendix C \& D).

The SART is a go/no-go task designed to measure sustained attention. Subjects are required to respond quickly to all non-target stimuli and withhold responses to target stimuli (Robertson, Manly, Andrade, Baddeley, \& Yiend, 1997). Subjects responded to non-target stimuli by pressing the spacebar. The non-target stimuli are words from one category (animals; 89\% of trials). Words from a second category, vegetables (11\% or trials) serve as the target stimulus (see McVay \& Kane, 2012). The SART consisted of 540 total trials, divided into 4 blocks, each containing 3 miniblocks of 45 trials. During each miniblock the task presented 40 non-target stimuli (animal names) and 5 target stimuli (vegetable names). These blocks are not apparent to the subjects. To the subjects this task appears to be one continuous block. On all trials, subjects are presented with a word for $300 \mathrm{~ms}$ followed immediately by a mask for $1500 \mathrm{~ms}$. Dependent measures for this portion of the task were $d$ ' (i.e., hit rate to animals minus false alarm rate to vegetables) is the standard deviation of reaction times to "go" (animals) trials.

I used the SART to measure the frequency and valence of mind wandering by having subjects complete imbedded thought probes ( 9 probes per block, 36 probes total). During the presentation of the thought probe, subjects were asked to respond to the prompt, "What were you just thinking about?" Response options included: “a. Task-related thoughts pertaining to the current task", "b. Task-related evaluative thoughts - positive," "c. Task-related evaluative thoughts - negative," “d. Task-unrelated thoughts, neutral content," “e. Task-unrelated thoughts, positive content," and "f. Task-unrelated thoughts, negative content." I operationalized mind wandering as thoughts unrelated to the task (TUTs). TUTs were calculated by summing all offtask response options selected and then dividing by the number of probes presented to calculate a percentage of off task thoughts (D, E, and F). I calculated rates for positive, negative, and neutral 
TUTs by summing each off-task response option individually (D, E, and F). Following these thought probes, subjects were asked about how off or on-task they were on a 5-point Likert scales. The responses to these probes are part of the larger project and are beyond the scope of this thesis and were not analyzed here.

\section{Questionnaires}

Life Experiences Survey (LES; Sarason, Johnson, \& Seigal, 1978; Appendix E). A selfreport questionnaire designed to measure the amount of life stress that a subject is experiencing. The LES presents 47 events (e.g., death of close friend, serious injury of close family member) and asks subjects to indicate whether or not the event occurred during the past 6 months. In this computerized version the subject saw two screens for every event. The first screen contained the prompt: "Have and when did you experience [the event]." This screen provided the following answer options: 1. Never; 2. 0-6 months ago; 3. 7-12 months ago; 4. Over 1 year ago. Following this screen subjects saw this prompt: "Indicate the extent to which you view the event as having either a positive or negative impact on your life" with the answer options of numbers ranging for -3 to +3 and "never experienced". Subjects responding to these prompts by pressing a number on the keyboard that corresponded with their intended answer. Sarason et al. (1979) report testretest reliabilities from 0.56 to 0.88 . The total number of negative life events endorsed on the LES was calculated by computing the sum of all negative ratings made by the subject.

\section{Ruminative Response Scale (Nolen-Hoeksema \& Morrow, 1991)}

Subjects were presented with 22 items related to ruminative response styles. These statements are either self-focused, focused on the consequences/causes of the subject's moods, or, or symptom focused. Subjects were asked to indicate how frequently each statement occurs on a scale of 1 (almost never) to 4 (almost always). Scores were obtained by summing all responses 
with higher scores indicating higher levels of rumination. For this scale, the alpha coefficient at Time 1 was .90 and the test-retest correlation was .67 (Treynor, Gonzalez, \& Nolen-Hoeksema, 2003).

\section{Trait level mindfulness}

Five Facet Mindfulness Questionnaire - Short Form (Bohlmeijer, ten Klooster, Fledderus, Veehof, \& Baer, 2011; Appendix F). A 24-item questionnaire designed to measure dispositional levels of mindfulness and encompasses five facets; observing (4 items), describing (5 items), acting with awareness (5 items), non-judging (5 items), and nonreactivity (5 items). Subjects are asked to rate their responses on a 5-point Likert-type scale ranging from 1 (never or very rarely true) to 5 (very often or always true). Scores are then added to form a total score.

High sores indicate more mindfulness. I used the total score (and not the facet scores) of this task in my analyses. The internal consistency (alpha) of this measure (overall) is between .70 and .91 (Bohlmeijer et al., 2011). 


\section{CHAPTER THREE: RESULTS}

Planned analyses for this thesis are contained in the prospectus (https://osf.io/xj25r/?view_only=69ce9d9a8812473a991139391f6a5ee4) and are a subset of the analyses in the preregistration (https://aspredicted.org/zp2w6.pdf). Unless otherwise indicated, all analyses were carried out using SPSS version 25 (IBM Corp., Armonk, NY). Linear mixed model (LMM) analyses were conducted in the R system for statistical analysis (R Core Team, 2017). LMMs were carried out using the lme4 package (Bates, Maechler, Bolker, \& Walker, 2015). Pvalues in the LMMs were computed using the Satterthwaite approximation contained in the lmerTest package (Kuznetsova, Brockhoff, \& Christensen, 2016). The Satterthwaite approximation has been shown to produce $p$ values in line with actual false positive rates (Luke, 2016). Bayes Factors (BF) for correlations used code provided in an online appendix to Wagenmakers, Verhagen, and Ly (2015; https://osf.io/cabmf). I use BFs to determine which model is more likely given the data.

\section{Data Loss}

I dropped all data for 2 subjects who were noncompliant with instructions across tasks. These decisions were made without consulting the subject's data. Due to computer error, I was missing data from 4 subjects in the operation span task. Additionally, 7 thought probe responses were removed for falling outside of the range of acceptable values (1-6). Seven subjects were removed for exceeding our preregistered criterion on the SART NTSD (one of which was already removed for being noncompliant with instructions). After accounting for NTSD criteria and subject $\log$ exclusions, 145 subjects were included in analyses. Not all subjects had a span score for each complex span task. For these subjects, WMC composites could not be formed so they were not included in analyses using this composite. For all analyses, I used the maximum 
amount of data available after accounting for data loss and exclusions, therefore Ns differ across analyses. Descriptive statistics and correlations for all variables can be seen in Table 1 and Table 2 , respectively. 
Table 1

Descriptive Statistics

\begin{tabular}{|c|c|c|c|c|c|c|c|}
\hline Variable & $\mathrm{N}$ & Minimum & Maximum & Mean & Std. Deviation & Skew & Kurtosis \\
\hline SART d' prime & 145 & -1.77 & 4.70 & 2.04 & 1.21 & -.32 & -.51 \\
\hline Mindfulness & 145 & 54.00 & 102.00 & 77.23 & 9.97 & -.05 & -.36 \\
\hline Mind Wandering & 145 & .00 & .97 & .34 & .26 & .55 & -.49 \\
\hline Negative TUTs & 145 & .00 & 30.00 & 2.57 & 4.93 & 3.13 & 11.36 \\
\hline Neutral TUTs & 145 & .00 & 26.00 & 6.85 & 6.23 & 1.00 & .46 \\
\hline SART NTSD & 145 & 66.32 & 376.81 & 170.67 & 52.57 & .97 & 1.58 \\
\hline OSPAN & 141 & -2.61 & 1.74 & .00 & 1.00 & -.44 & -.28 \\
\hline Positive TUTs & 145 & .00 & 19.00 & 2.87 & 3.80 & 2.13 & 5.19 \\
\hline Rumination & 145 & 25.00 & 84.00 & 51.06 & 12.87 & .43 & -.62 \\
\hline SYMSPAN & 145 & -2.88 & 1.71 & .00 & 1.00 & -.38 & -.21 \\
\hline Negative life events & 145 & .00 & 32.00 & 9.77 & 6.62 & 1.04 & 1.11 \\
\hline $\begin{array}{l}\text { Working Memory } \\
\text { Capacity }\end{array}$ & 141 & -2.33 & 1.56 & .01 & .82 & -.41 & .03 \\
\hline
\end{tabular}

Note: OSPAN = Operation Span z-score; SYMSPAN = symmetry span z-score; SART = Semantic Sustained Attention To Response Task; TUTs $=$ task unrelated thoughts; NTSD = non-target response time standard deviation 
Table 2

Correlations $(\mathrm{N}=145)$

\begin{tabular}{|c|c|c|c|c|c|c|c|c|c|c|c|c|}
\hline Variables & 1 & 2 & 3 & 4 & 5 & 6 & 7 & 8 & 9 & 10 & 11 & 12 \\
\hline 1. Working Memory Capacity & - & & & & & & & & & & & \\
\hline 2. Negative Life Events & .04 & - & & & & & & & & & & \\
\hline 3. OSPAN & .83 & .11 & - & & & & & & & & & \\
\hline 4. SYMSPAN & .83 & -.07 & .37 & - & & & & & & & & \\
\hline 5. Mind Wandering & -.10 & .09 & -.12 & -.05 & - & & & & & & & \\
\hline 6. SART d' Prime & .23 & .07 & .22 & .15 & -.18 & - & & & & & & \\
\hline 7. SART NTSD & -.25 & .03 & -.25 & -.16 & .31 & -.28 & - & & & & & \\
\hline 8. Positive TUTs & -.04 & .07 & -.04 & -.01 & .45 & -.14 & .09 & - & & & & \\
\hline 9. Neutral TUTs & -.05 & .03 & -.06 & -.05 & .72 & -.06 & .19 & .00 & - & & & \\
\hline 10. Negative TUTs & -.09 & .07 & -.12 & -.03 & .62 & -.16 & .27 & .08 & .09 & - & & \\
\hline 11. Mindfulness & .09 & .10 & .18 & -.06 & -.21 & .05 & -.08 & .05 & -.19 & -.19 & - & \\
\hline 12. Rumination & -.09 & .09 & -.12 & -.03 & .22 & .04 & .20 & -.05 & .21 & .18 & -.52 & - \\
\hline
\end{tabular}

Note: OSPAN = Operation Span z-score; SYMSPAN = symmetry span z-score; SART= Semantic Sustained Attention To Response Task; TUTs $=$ task unrelated thoughts; NTSD $=$ non-target response time standard deviation 


\section{Correlations}

In addition to the frequentist interpretation of these correlations I also examined them using Bayes Factors. To this end, I computed a BF for each correlation. The BF allows to me assess if the correlation produced from the data in this experiment is more likely to occur if it came from a point-null distribution (i.e., null hypothesis) or from a Cauchy distribution where $50 \%$ of the distribution lies between -.33 and .33 (i.e., the alternative hypothesis). Here numbers greater than one support the alternative hypothesis and numbers less than one support the null hypothesis that the correlation is more likely from the point-null distribution $(r=0)$. Negative life event stress was not significantly correlated with working memory capacity, $r(139)=.04, p$ $=.63,95 \%$ Confidence Interval $(C I)[-.13, .20], B F_{10}=.22$, with data being more consistent with the null hypothesis by a factor of 5 (see Figure 1), or mind wandering, $r(143)=.09, p=.31$, $95 \% C I[-.08, .25], B F_{10}=.32$, with data being more consistent with the null hypothesis by a factor of 3 (see Figure 2).

Klein and Boals (2001) suggested (but did not do any statistical tests to confirm) that negative life event stress is more impactful to working memory capacity when the working memory task is more difficult (i.e. lengthier set sizes; $r=-.38$ for a set size of seven vs. $r=-.21$ for set sizes of five and six). Although not listed as part of the proposed analyses, I explored this relationship by calculating subject's scores on the highest two set sizes per span task (OSPAN = 6 and 7; SYMMSPAN $=4$ and 5). The longest OSPAN scores correlated with total OSPAN scores at $r(138)=.88, p<.001$, and the longest SYMSPAN scores correlated with total SYMSPAN scores at $r(143)=.93, p<.001$. The most difficult trials were not strongly associated with negative LES $(r(138)=.08, p=.34$ for OSPAN and $r(143)=-.09, p=.26$ for 
SYMMSPAN). Additionally, after z-scoring and making a working memory composite score using only the most difficult trials, the correlation with LES was $r(138)=.01, p=.90$.

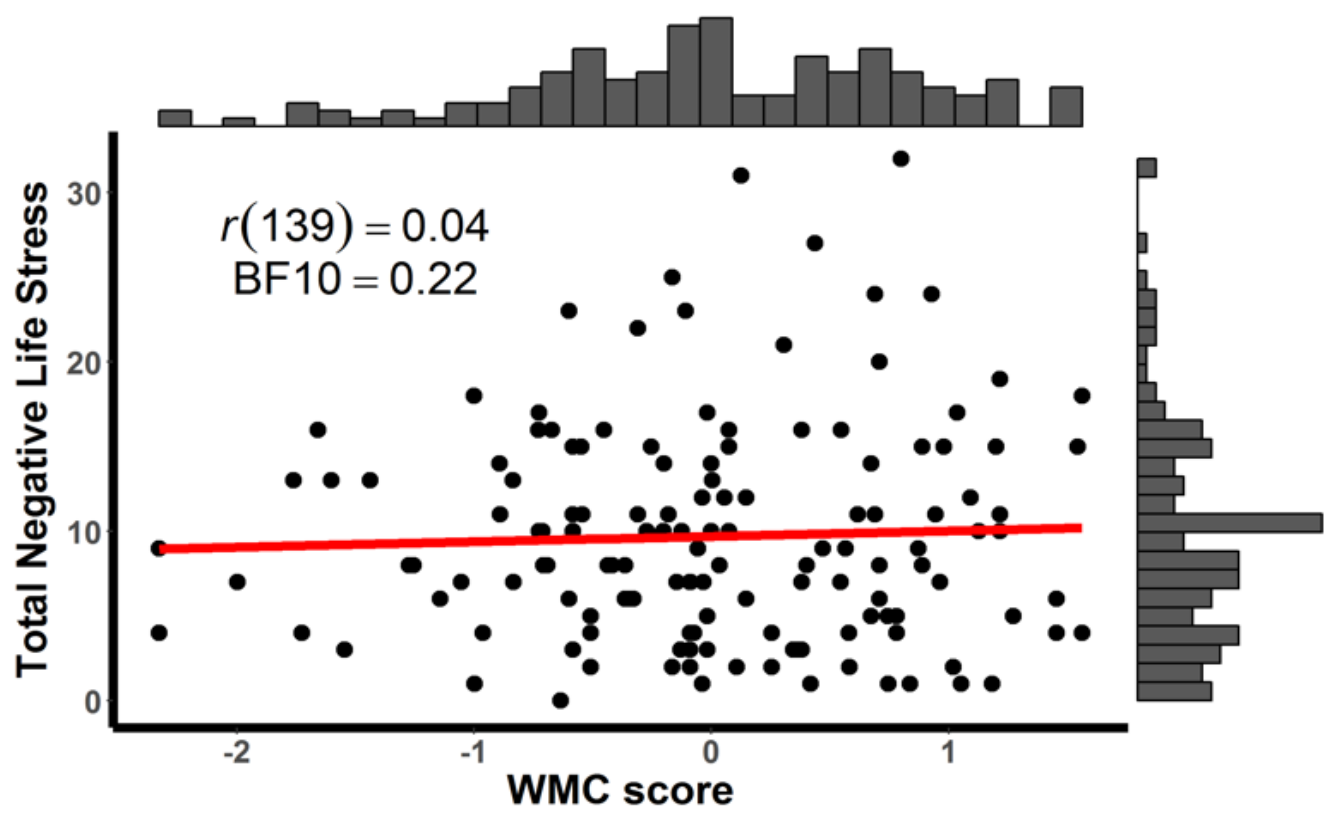

Figure 1. Correlation between total negative life event stress and working memory capacity (WMC). Histograms for each variable are presented across from each axis. BF10 = Bayes Factor with numbers less than one favoring the null hypothesis and numbers greater than one favoring the alternative hypothesis. 


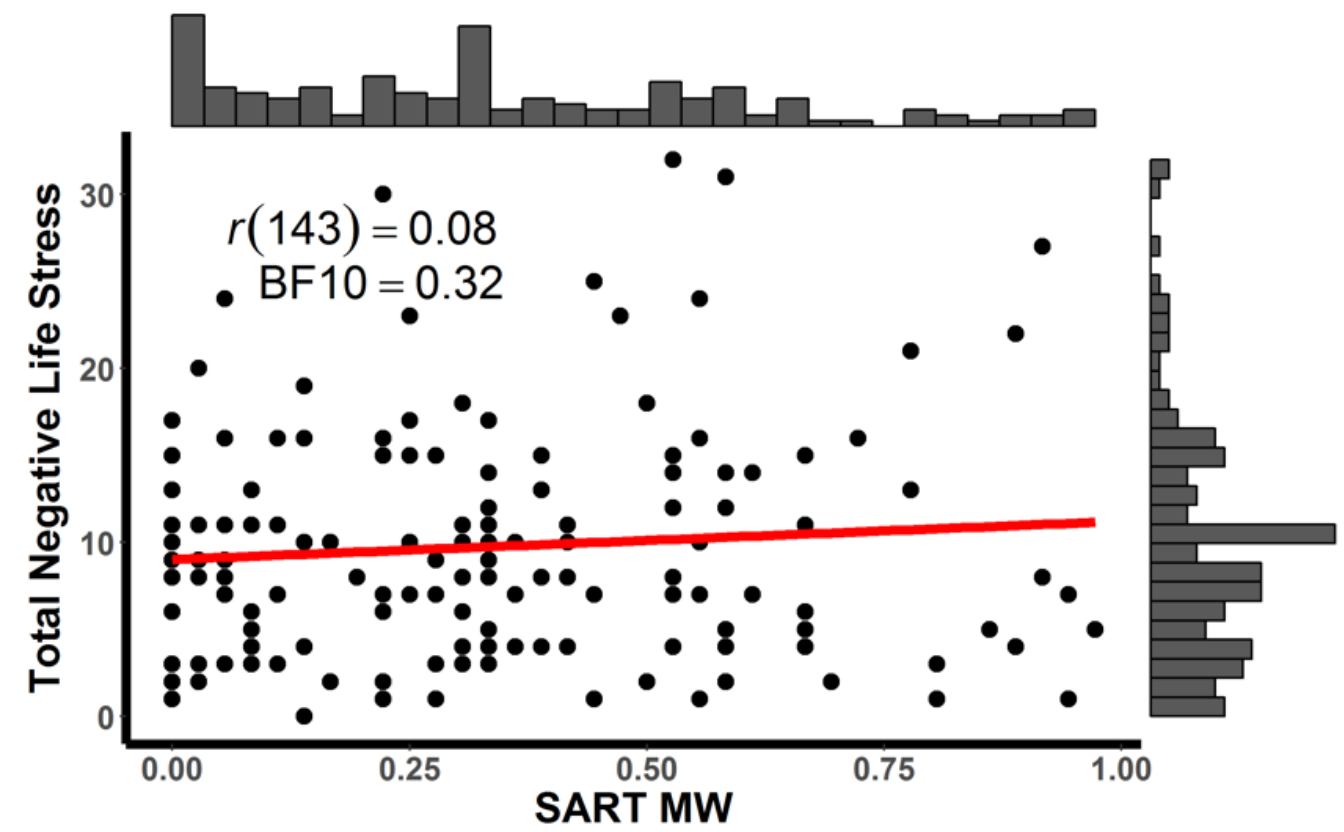

Figure 2. Correlation between total negative life event stress and SART mind wandering (MW). Histograms for each variable are presented across from each axis. BF10 = Bayes Factor with numbers less than one favoring the null hypothesis and numbers greater than one favoring the alternative hypothesis.

\section{Linear Mixed Models}

To test if negatively-valenced mind wandering is more disruptive to performance relative to positively-valenced and neutral mind wandering as found in Banks et al. (2016), I conducted separate linear mixed models predicting nontarget response time standard deviation (RTSD) and SART target accuracy. In my model predicting RTSD, I included all probe trials that were preceded by four consecutive nontarget trials where a response time (RT) was recorded. The RTSD in these models is the standard deviation of these four trials. One reason to examine RTSD in addition to accuracy are concerns about mind wandering reports being reactive to how the subject performed on the preceding target trial. Subjects are generally aware that they have made an error, but it is assumed that subjects are not aware of the RT variability preceding the target trial. Thus, to be confident that valence is driving the relation with impaired performance (and not the other way around), negatively-valenced thought probes should negatively predict 
performance in both models above and beyond the other off-task reports. The model predicting accuracy was a generalized linear-mixed model (GLMM) to account of the dichotomous outcome variable (i.e., accurate or not). Linear mixed models accommodate unbalanced data without a loss of power and account for the non-independence of data by using subjects as a random variable (Kliegl, Wei, Dambacher, Yan, \& Zhou, 2010). These models used random intercept and slope as a more maximal random effects structure prevents alpha inflation (Barr, 2013). In these models, neutrally-valenced probes are the reference level.

In the model predicting RTSD, positively, $\mathrm{b}=2.46, \mathrm{SE}=8.56, \mathrm{t}=.3, p=.22$, and negatively-valenced thought probe responses, $\mathrm{b}=-9.94, \mathrm{SE}=9.12, \mathrm{t}=1.1, p=.28$, did not predict unique variance in RTSD above and beyond neutrally-valanced probes (see Figure 3). In a post-hoc test, negatively-valenced and positively-valenced responses did not significantly differ from each other, $\mathrm{b}=-7.48, \mathrm{SE}=11.56, \mathrm{t}=-.65, p=.52$. But in the model predicting accuracy, negatively-valenced response, $\mathrm{b}=-0.63, \mathrm{SE}=.19, \mathrm{z}=-3.3, p=.001$ predicted unique variance in accuracy compared to neutrally-valenced responses while positively-valenced thought probe response did not, $\mathrm{b}=-.22, \mathrm{SE}=.16, \mathrm{z}=-1.3, p=.18$. In this model, negatively and positively also did not significantly differ from one another, $\mathrm{b}=.41, \mathrm{SE}=.21, \mathrm{z}=1.9, p=$ .057 .

Table 3

Mixed Linear Models with Positively and Negatively Valanced Mind Wandering, Compared to Neutral Mind Wandering, as Predictors of Response Time Variability in the SART

\begin{tabular}{lccccc}
\multicolumn{1}{c}{ Predictor } & estimate & Std. Error & df & $t$ value & $p$ \\
\hline (Intercept) & 102.78 & 4.63 & 102.75 & 22.22 & $<.001$ \\
Positive Mind Wandering & 2.46 & 8.46 & 74.72 & 0.29 & 0.77 \\
Negative Mind Wandering & 9.94 & 9.12 & 52.60 & 1.09 & 0.28 \\
\hline
\end{tabular}




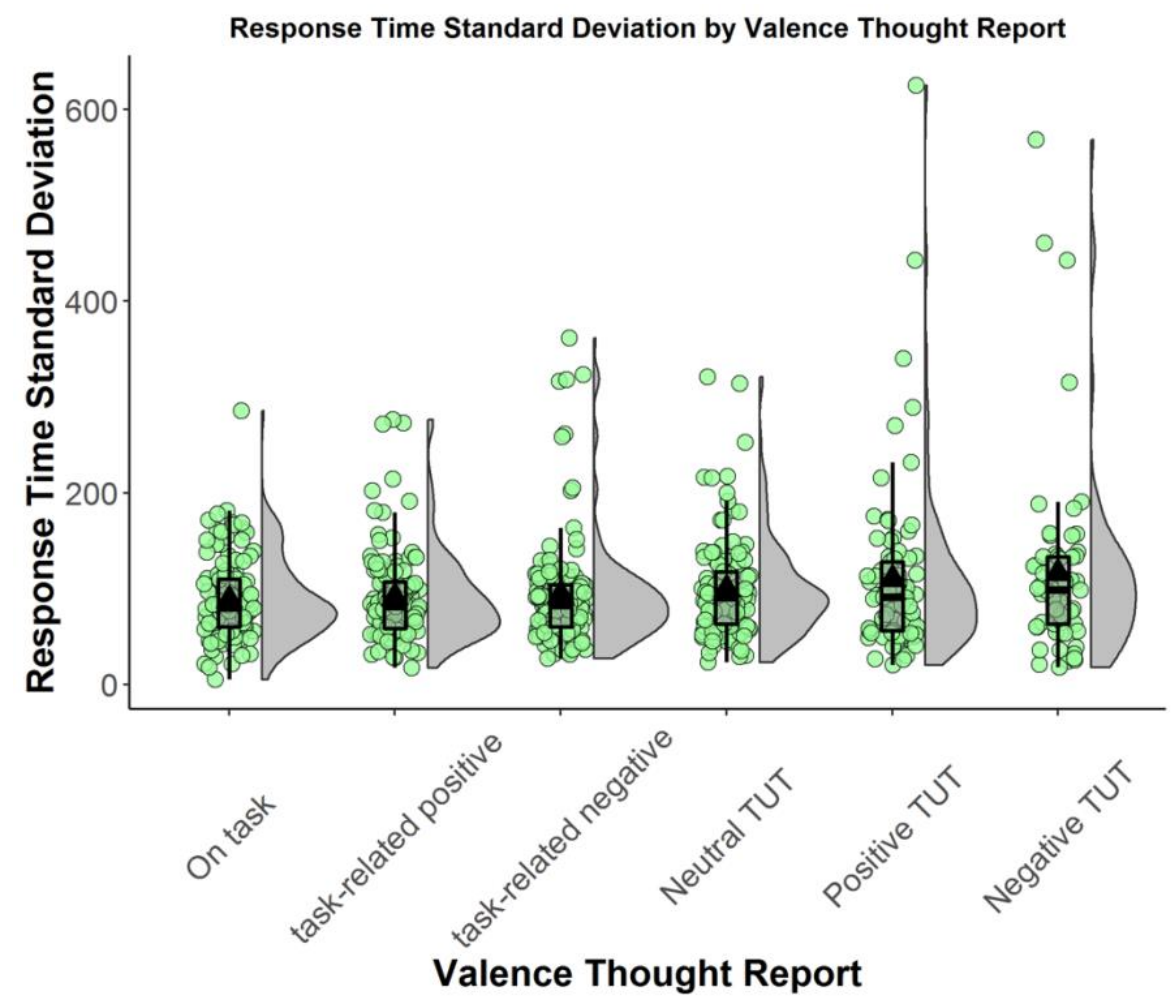

Figure 3. Green-filled circles represent subject means. Triangles are the distribution mean. Horizontal lines in the middle of the box are the median. Lower Hinge represents the $25 \%$ of the distribution and the upper hinge represents the $75 \%$ of the distribution. The whiskers extend 1.5 times the interquartile range from the upper and lower hinges. To the right of boxes and circles are density distributions of subject means. TUT $=$ task unrelated thought

Table 4

Generalized Mixed Linear Models with Positively and Negatively Valanced Mind Wandering, Compared to Neutral Mind Wandering, as Predictors of SART Accuracy

\begin{tabular}{lcccc}
\multicolumn{1}{c}{ Predictor } & estimate & Std. Error & $z$ value & $p(>|\mathrm{z}|)$ \\
\hline (Intercept) & 0.13 & 0.17 & 22.22 & 0.42 \\
Positive Mind Wandering & -0.22 & 0.16 & -1.33 & 0.18 \\
Negative Mind Wandering & -6.63 & 0.19 & -3.25 & 0.001 \\
\hline
\end{tabular}




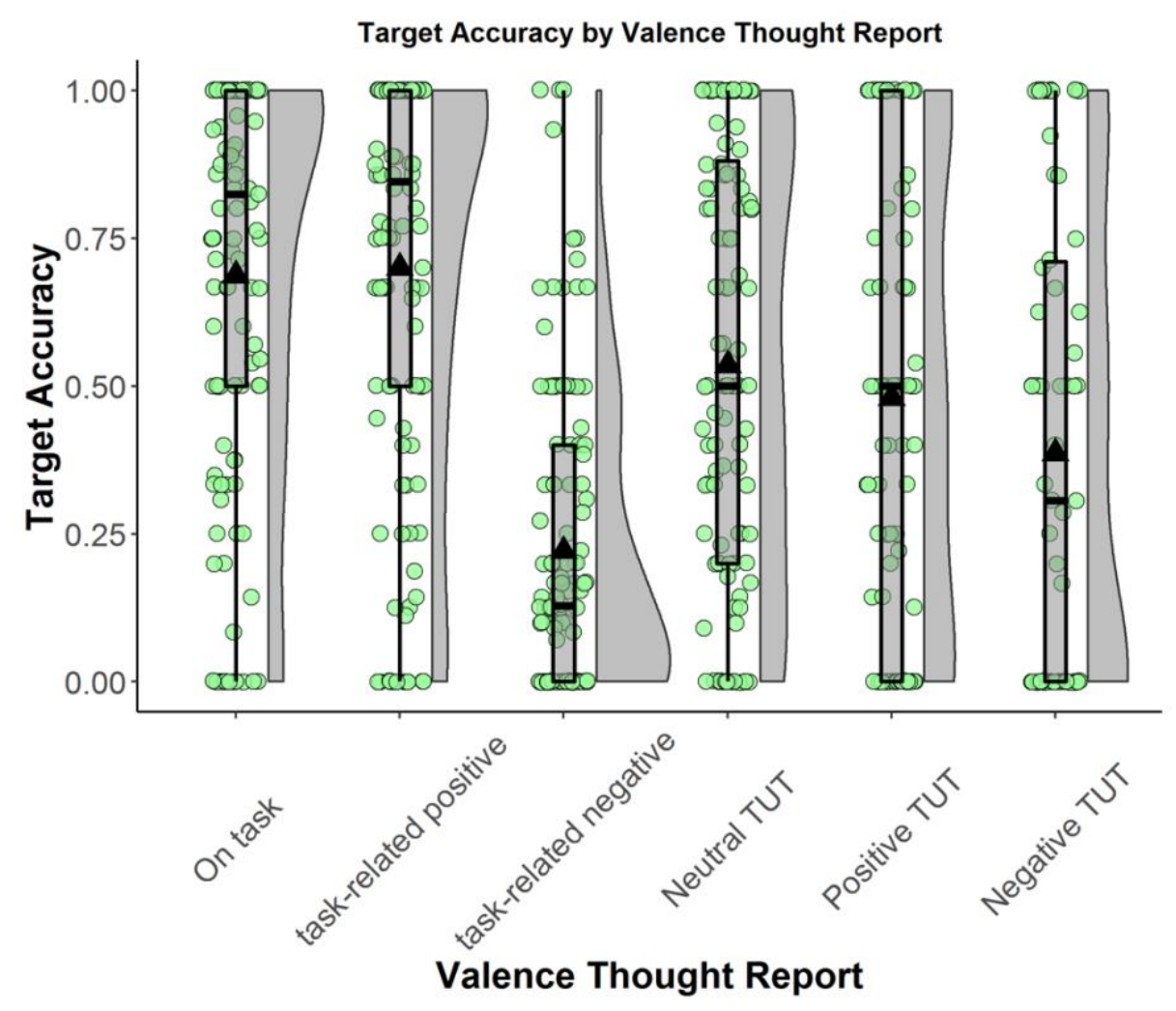

Figure 4. Green-filled circles represent subject means. Triangles are the distribution mean. Horizontal lines in the middle of the box are the median. Lower Hinge represents the $25 \%$ of the distribution and the upper hinge represents the $75 \%$ of the distribution. The whiskers extend 1.5 times the interquartile range from the upper and lower hinges. To the right of boxes and circles are density distributions of subject means. TUT $=$ task unrelated thought

\section{Mediation Analyses}

Although, I did not detect an association between life event stress in the correlation analysis; it remains possible that life event stress is associated with working memory capacity through a mediating process and this indirect effect is masked by unidentified countervailing effects (Zhao, Lynch Jr, \& Chen, 2010). That is, life event stress may have an effect on working memory that is masked by opposing forces. In separate models, I tested if either overall mind wandering propensity, the sum of negatively-valenced thought reports, or rumination statistically mediates the relation between negative life events and working memory capacity. Analyses were 
conducted with PROCESS macro 4 (Hayes, 2017) using SPSS 25.0.0 (IBM Corp., Armonk, NY) on the model shown in Figure 5a, 5b, and 5c, respectively. Nonparametric bootstrapping with 5,000 samples provided estimation of both direct and indirect effects (Preacher \& Hayes, 2008). Mediation is present if the bootstrap confidence interval for the indirect effect does not include zero (Hayes \& Rockwood, 2017). 
Table 5

Mediation Analysis Results Examining Total TUTs, Negative TUTs, and Rumination as Mediators for the Impact of Negative Life Events Stress on Working Memory Capacity.

\begin{tabular}{lcccccccccc} 
& \multicolumn{10}{c}{ Path } \\
\cline { 2 - 10 } Mediator & $\mathrm{a}$ & $95 \% \mathrm{CI}$ & $\mathrm{b}$ & $95 \% \mathrm{CI}$ & $\mathrm{c}$ & $95 \% \mathrm{CI}$ & $\mathrm{c}^{\prime}$ & $95 \% \mathrm{CI}$ & $\begin{array}{c}\text { Indirect } \\
\text { effect }\end{array}$ & $95 \% \mathrm{CI}$ \\
\hline & & & & & & & & & & \\
Total TUTs & 0.00 & $-0.01,0.01$ & -0.32 & $-0.85,0.20$ & 0.01 & $-0.01,0.02$ & 0.01 & $-0.01,0.20$ & -0.00 & $-0.01,0.03$ \\
Negative TUTs & 0.05 & $-0.09,0.23$ & -0.02 & $-0.05,0.01$ & 0.01 & $-0.01,0.02$ & 0.01 & $-0.01,0.02$ & -0.00 & $-0.01,0.00$ \\
Rumination & 0.19 & $-0.15,0.54$ & -0.01 & $-0.02,0.01$ & 0.01 & $-0.01,0.02$ & 0.01 & $-0.01,0.03$ & -0.00 & $-0.01,0.00$ \\
\hline
\end{tabular}

Note. Values represent unstandardized path coefficients. $\mathrm{a}=$ path from negative life events stress to mediator.; $\mathrm{b}=$ path from the mediator to working memory capacity; $\mathrm{c}=$ path from negative life events stress to working memory capacity; $c^{\prime}=$ path from negative life events to working memory capacity controlling for the indirect effect through the mediator; Total TUT = proportion of task unrelated thoughts; Negative TUT $=$ sum of negatively valanced mind wandering; $\mathrm{CI}=$ confidence interval.
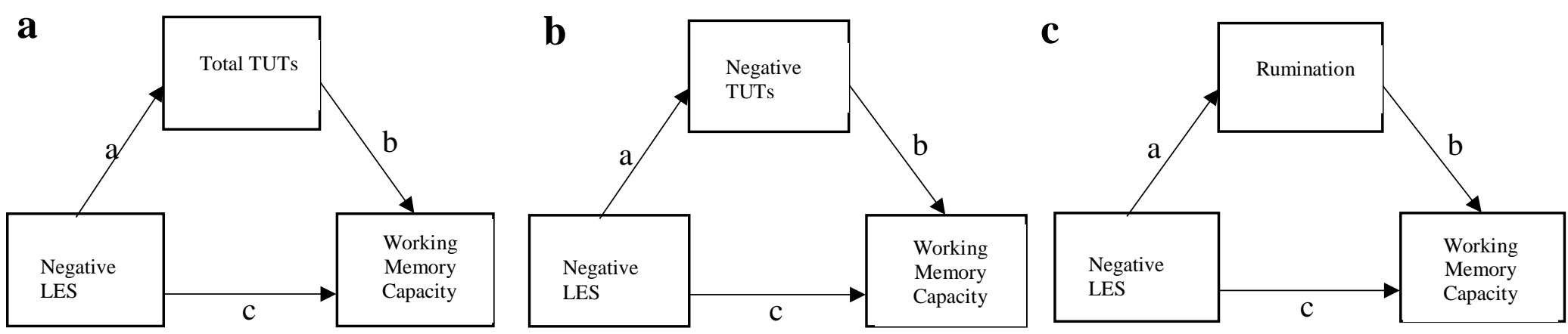

Figure 5. (a, b, c) Mediation models. LES = life event stress, TUTs = task unrelated thoughts. 
As seen in Table 5, negative life events were not associated with total TUTS, $b=0.004$, $\mathrm{SE}=0.003, t(139)=1.12, p=.29,95 \%$ CI $[-0.004,0.01]$, Negative TUTs, $b=0.05, \mathrm{SE}=0.07$, $t(139)=.84, p=.50,95 \% \mathrm{CI}[-.09,0.23]$, or rumination, $b=0.19, \mathrm{SE}=0.17, t(139)=1.09, p=$ $.28,95 \%$ CI $[-0.15,0.54]$. Additionally, none of the mediators significantly predicted working memory capacity (total TUTs, $b=-0.32, \mathrm{SE}=0.27, t(139)=-1.21, p=.23,95 \% \mathrm{CI}[-.0 .85$, $0.20]$, negative TUTs, $b=-0.02, \mathrm{SE}=0.01, t(139)=-1.16, \mathrm{p}=.25,95 \% \mathrm{CI}[-0.05,0.01]$, and rumination, $b=-.01, \mathrm{SE}=0.01, t(139)=-1.09, p=.28,95 \% \mathrm{CI}[-0.02,0.01])$. Finally, Total TUTs, $b=-0.001,95 \%$ CI [-0.01, 0.03], negative TUTs, $b=-0.001,95 \%$ CI [-0.01 - 0.001], and rumination, indirect effect $=-0.001,95 \%$ CI $[-0.007-0.001]$, did not serve as significant mediators for an indirect effect of negative life event stress on working memory capacity.
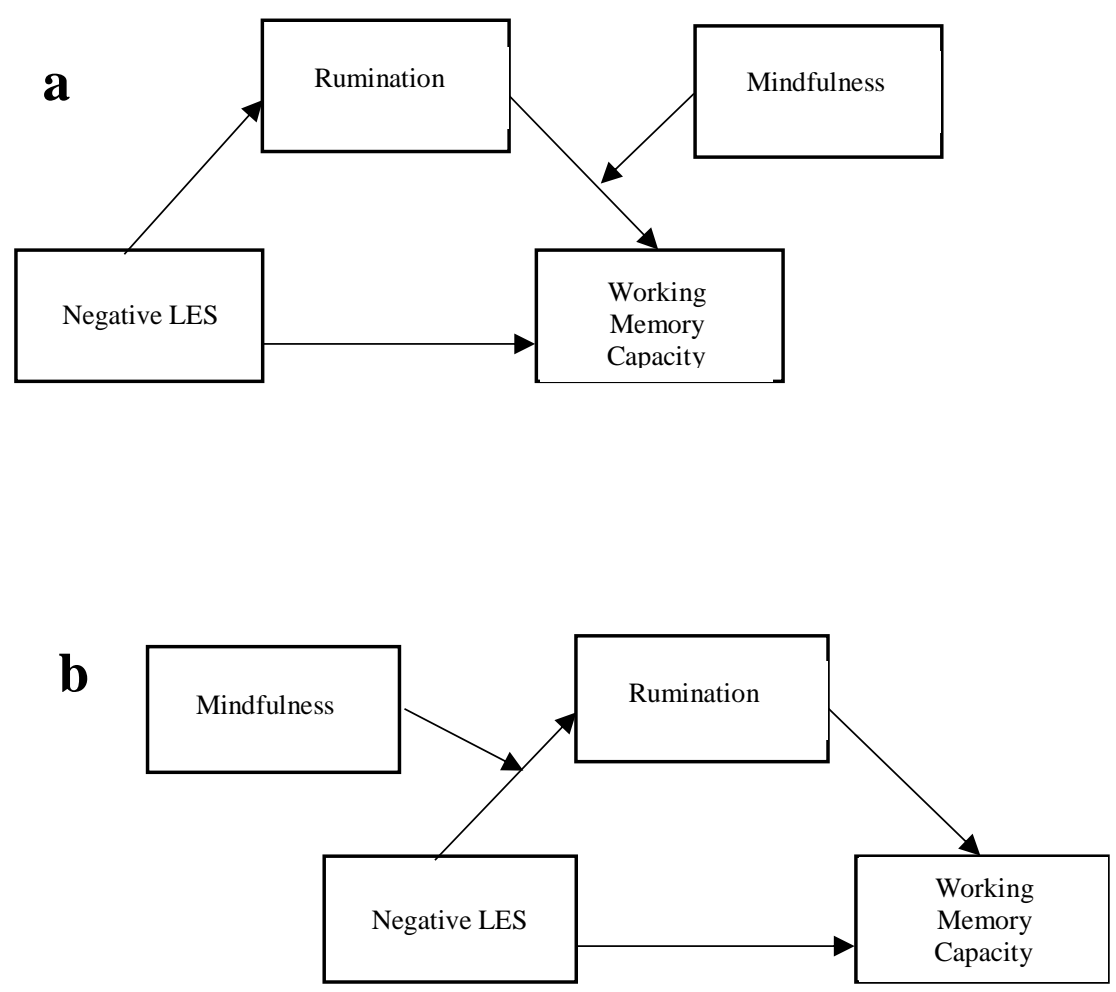

Figure 6. (a, b) Moderated mediation models. LES = life event stress. 
To determine whether the indirect effect of negative life events stress on working memory capacity through rumination was moderated by mindfulness, I conducted a moderated mediation analysis using the PROCESS macro for SPSS (Hayes, 2013). After testing the model shown in figure $5 \mathrm{c}$, rumination was added as a moderator (see Figure $6 \mathrm{a}$ and $6 \mathrm{~b}$ ). The indirect effect of negative life events on working memory capacity through rumination was not observed, indirect effect $=-0.001,95 \% \mathrm{CI}[-0.007-0.001]$. This suggests that rumination does not serve as a mediator. The confidence interval of the index of moderated mediation did include zero, $B=-$ $0.00002,95 \%$ CI for $B[-.0 .0004,0.0002]$, indicating that mindfulness does not significantly moderate the indirect effect. 


\section{CHAPTER FOUR: DISCUSSION}

Klein and Boals (2001) provided evidence that experiencing negative life events impairs working memory capacity as measured by scores on both the LES and the operation span task (Turner \& Engle, 1989). Here, I found evidence inconsistent with the claim that negative life event stress impairs working memory capacity. In the current study, the correlation between life event stress and working memory capacity favored the null hypothesis over the alternative hypothesis (i.e., $r \neq 0$ ) by a factor of five. Because Klein and Boals (2001) speculated that the effects of life event stress may be particularly damaging to more difficult cognitive operations, I correlated life event stress with subjects' performance on the two longest set sizes. Here again, I found no evidence of an association between life event stress and working memory capacity. In addition to the correlations, I conducted mediation analyses that allowed me to assess if life event stress had an indirect effect through the potential mediators of mind wandering propensity, sum of negative thoughts, or ruminative response style. In none of these analyses, did negative life event stress have an indirect effect. There are multiple reasons why an effect may not replicate.

One potential reason is that, even in a perfectly replicated study, there is a chance that a true effect can be missed because of a lack of statistical power. However, the use of the Bayesian framework (with the correlations) allowed us to accrue evidence in favor of the null hypothesis, which alleviates some of these concerns. Another reason that a study can fail to replicate is that the effect found in original work may have been a false positive or smaller than the original estimate (related to the power issues mentioned above). Finally, an effect may fail to replicate if the conditions of the original study were not re-created in the replicating study. 
Although I cannot definitively adjudicate between these alternative explanations, Gelman's (2016) time-reversal heuristic offers a guide about how to think about the differences between the two studies. If this current study had been reported first with evidence supporting no relation between working memory capacity and cumulative negative life event stress from a substantially larger sample, better measurement practices, a preregistered analysis plan, and using both frequentist and Bayesian analyses and then Klein and Boals reported their findings of the negative association between life stress and working memory capacity with inadequate sample sizes ( $\mathrm{N}=22$ and $\mathrm{N}=66)$ and no preregistered analysis plan, which study would one be inclined to believe? In addition, Banks (2011) and Banks and Boals (2016) did not show a direct relationship between life even stress and working memory capacity, suggesting that experiencing negative life events does not cause working memory impairments. Another goal of this study was to test a potential mechanism through which negative life event stress may hurt working memory capacity. As reported above in the mediation models, neither mind wandering propensity, sum of negatively-valenced mind wandering reports, or rumination response style carried a significant amount of variance between negative life event stress and working memory capacity. In addition to these analyses, I also examined more directly the effects of negatively-valenced off-task responses on performance in the SART task. This analysis is more direct because it did not require the life event stress variable. The question being asked in these analyses is if negatively-valenced off-task thought response uniquely related to SART performance above and beyond positively and neutrally-valenced off-task thought reports.

Previously Banks et al. (2016) produced some evidence that negatively-valenced thought reports were more deleterious to performance in working memory and sustained attention tasks relative to positive but not neutral thought reports. Here, when examining accuracy I found that 
negatively-valenced off-task reports predicted worse accuracy than neutrally-valenced but not positively-valenced off-task thought reports. However, in the model predicting RTSD, no such differences were seen between the different off-task thought valances. These results taken together suggest that association between negatively-valenced off-task reports and accuracy may be not be evidence for negatively-valenced off-task thoughts being more damaging to performance but may reflect reactivity in the sense that subjects' thought reports may be influenced by the accuracy of the proximal target response. That is, failing to withhold a response to a target (thus being inaccurate) induces negative affect, which then guides the subject report being off-task with a negatively valenced thought.

In my analyses, trait level mindfulness and rumination did not function as mediators. However, correlational analyses indicated that mind wandering was negatively correlated with mindfulness and positively correlated with rumination indicating that these two constructs are important components when attempting to conceptualize mind wandering. Furthermore the negative correlation between mind wandering and mindfulness, provides some evidence for the nonjudgmental and present moment awareness components of trait level mindfulness.

Rumination was more strongly associated with negative and neutral, but not positive mind wandering, also indicating that this "clinical" construct also plays a role in cognitive functioning. Although not statistically significant, these correlations indicate that trait level mindfulness and rumination are both constructs that should when considering the relationship between working memory capacity and mind wandering. Continuing to include them in cognitive research will help yield more ecologically valid findings.

\section{Conclusion}


My findings do not support the claim that cumulative negative life event stress impairs working memory capacity. To be clear, I am not suggesting that there is no evidence that any and all stress does not negatively impact working memory capacity; rather that the evidence base for cumulative negative life event stress is suspect and (unless it becomes more established) should not be used as the motivation for or justification of future work. The evidence base for the effects of acute in-the-moment stress negatively impacting working memory capacity seems much more secure (see: Banks \& Boals, 2016; Schoofs et al., 2008; Sliwinski et al., 2006; Qin, Hermans., van Marle, Luo, Fernández, 2009). The research suggesting that prolonged exposure to stress has the potential to negatively impact to physical and emotional health is also well supported (Cohen et al., 2019).

Future research should continue to explore the relationship between TUT valance, working memory capacity, and mindfulness. I did provide some evidence that negative TUTs are more impactful to performance on SART accuracy when compared to neutrally but not positively valanced TUTs. This has several clinical and practical implications. For example, ruminative response styles (persistent negative TUTs) are a key component of the depressive disorders (Nolen-Hoeksema et al., 2008). Cognitive deficits are also a key component of depressive disorders (American Psychiatric Association, 2013). Mindfulness based cognitive therapy for depression has emerged as a promising treatment modality, encouraging present moment awareness and a nonjudgmental disposition (Segal, Williams, \& Teasdale, 2018). By exploring the relationship between working memory impairments, negative mind wandering, and mindfulness, an greater understanding of the mechanisms by which mindfulness functions as a treatment modality may be better understood, facilitation improvements in patient outcomes. 


\section{REFERENCES}

American Psychiatric Association. (2013). Diagnostic and statistical manual of mental disorders (DSM-5®). American Psychiatric Pub.

Baddeley, A., \& Idzikowski, C. (1985). Anxiety, manual dexterity and diver performance. Ergonomics, 28(10), 1475-1482.

Banks, J. (2011). Is mind wandering the mechanism responsible for life stress induced impairments in working memory capacity? (Doctoral dissertation, University of North Texas).

Banks, J. B., \& Boals, A. (2016). Don't think about it: Understanding the role of mind wandering in stress related working memory impairments. Cognition and Emotion, doi: $10.1080 / 02699931.2016 .1179174$

Banks, J. B., Tartar, J. L., \& Welhaf, M. (2014). Where's the Impairment: An Examination of Factors that Impact Sustained Attention Following a Stressor. Cognition and Emotion, 28, 856-866. DOI: 10.1080/02699931.2013.857643

Banks, J. B., Welhaf, M. S., \& Srour, A. (2015a). The protective effects of brief mindfulness meditation training. Consciousness and Cognition, 33, 277-285.

Banks, J. B., Welhaf, M. S., Hood, A. V. B., Boals, A., \& Tartar, J. L. (2016). Examining the role of emotional valence of mind wandering: All mind wandering is not equal. Consciousness and Cognition, 43, 167-176.

Banks, J., B., Tartar, J. L., \& Tamayo, B. A. (2015). Examining factors involved in stress related working memory impairments: Independent or conditional effects? Emotion, 15(6), 827836. 
Barr, D. J. (2013). Random effects structure for testing interactions in linear mixed-effects models. Frontiers in psychology, 4, 328.

Bates, D., Maechler, M., Bolker, B., Walker, S., Christensen, R. H. B., \& Singmann, H. (2015). lme4: Linear mixed-effects models using Eigen and S4, 2014. R package version, 1(4).

Baum, A., \& Posluszny, D. M. (1999). Health psychology: mapping biobehavioral contributions to health and illness. Annual Review of Psychology, 50(1), 137-163.

Bohlmeijer, E., ten Klooster, P. M., Fledderus, M., Veehof, M., \& Baer, R. (2011). Psychometric properties of the five facet mindfulness questionnaire in depressed adults and development of a short form. Assessment, 18(3), 308-320.

Chambers, R., Lo, B. C. Y., \& Allen, N. B. (2008). The impact of intensive mindfulness training on attentional control, cognitive style, and affect. Cognitive Therapy and Research, 32(3), $303-322$.

Christoff, K., Gordon, A. M., Smallwood, J., Smith, R., \& Schooler, J. W. (2009). Experience sampling during fMRI reveals default network and executive system contributions to mind wandering. Proceedings of the National Academy of Sciences, 106(21), 87198724.

Cohen S, Gianaros PJ, \& Manuck SB (2016). A stage model of stress and disease. Perspect. Psychol. Sci. 11:456-63

Cohen, S., Murphy, M. L., \& Prather, A. A. (2019). Ten surprising facts about stressful life events and disease risk. Annual review of psychology, 70, 577-597.

Constantino, R. E., Sekula, L. K., Rabin, B., \& Stone, C. (2000). Negative life experiences negative life experiences, depression, and immune function in abused and nonabused women. Biological Research for Nursing, 1(3), 190-198. 
Conway, A. R. A., Kane, M. J., Bunting, M. F., Hambrick, D. Z., Wilhelm, O., \& Engle, R. W. (2005). Working memory span tasks: A methodological review and user's guide. Psychonomic Bulletin and Review, 12, 769-786. doi: 10.3758/BF03196772

Daneman, M., \& Carpenter, P. A. (1980). Individual differences in working memory and reading. Journal of verbal learning and verbal behavior, 19(4), 450-466.

Engle, R. W. (2002). Working memory capacity as executive attention. Current directions in psychological science, 11(1), 19-23.

Foster, J. L., Shipstead, Z., Harrison, T. L., Hicks, K. L., Redick, T. S., \& Engle, R. W. (2015). Shortened complex span tasks can reliably measure working memory capacity. Memory \& cognition, 43(2), 226-236.

Gellman (2016, January 26). The time-reversal heuristic — a new way to think about a published finding that is followed up by a large, preregistered replication (in context of claims about power pose) [Blog post]. Retrieved from https://statmodeling.stat.columbia.edu/2016/01/26/more-power-posing/

Hambrick, D. Z., Oswald, F. L., Darowski, E. S., Rench, T. A., \& Brou, R. (2010). Predictors of multitasking performance in a synthetic work paradigm. Applied Cognitive Psychology, 24(8), 1149-1167.

Hayes, A. F. (2017). Introduction to mediation, moderation, and conditional process analysis: A regression-based approach. Guilford Publications.

Hayes, A. F., \& Rockwood, N. J. (2017). Regression-based statistical mediation and moderation analysis in clinical research: Observations, recommendations, and implementation. Behaviour research and therapy, 98, 39-57. 
Hoffmann, F., Banzhaf, C., Kanske, P., Bermpohl, F., \& Singer, T. (2016). Where the depressed mind wanders: Self-generated thought patterns as assessed through experience sampling as a state marker of depression. Journal of affective disorders, 198, 127-134.

Hoffmann, F., Viding, E., Puetz, V. B., Gerin, M. I., Sethi, A., Rankin, G., \& McCrory, E. J. (2018). Evidence for depressogenic spontaneous thoughts and altered resting-state connectivity in adolescents with a maltreatment history. Journal of the American Academy of Child \& Adolescent Psychiatry.

Hyun, J., Sliwinski, M. J., \& Smyth, J. M. (2018). Waking Up on the Wrong Side of the Bed: The Effects of Stress Anticipation on Working Memory in Daily Life. The Journals of Gerontology: Series B.

IBM Corp. Released 2017. IBM SPSS Statistics for Windows, Version 25.0. Armonk, NY: IBM Corp.

Jha, A. P., Morrison, A. B., Parker, S. C., \& Stanley, E. A. (2016). Practice is protective: Mindfulness training promotes cognitive resilience in high-stress cohorts. Mindfulness, 7(1), 1-13. doi: 10.1007/s12671-015-0465-9.

Jha, A. P., Stanley, E. A., Kiyonaga, A., Wong, L., \& Gelfand, L. (2010). Examining the protective effects of mindfulness training on working memory capacity and affective experience. Emotion, 10(1), 54.

Joormann, J., \& Gotlib, I. H. (2008). Updating the contents of working memory in depression: Interference from irrelevant negative material. Journal of Abnormal Psychology, 117(1), 182. 
Joormann, J., Levens, S. M., \& Gotlib, I. H. (2011). Sticky thoughts: depression and rumination are associated with difficulties manipulating emotional material in working memory. Psychological Science, 22(8), 979-983.

Kabat-Zinn, J. (1994). Mindfulness-based interventions in context: Past, present, \& future, Clinical Psychology: Science and Practice, 10, 144, 156.

Kane, M. J., \& Engle, R. W. (2003). Working-memory capacity and the control of attention: the contributions of goal neglect, response competition, and task set to Stroop interference. Journal of Experimental Psychology: General, 132(1), 47.

Kane, M. J., Hambrick, D. Z., Tuholski, S. W., Wilhelm, O., Payne, T. W., \& Engle, R. W. (2004). The generality of working memory capacity: a latent-variable approach to verbal and visuospatial memory span and reasoning. Journal of Experimental Psychology: General, 133(2), 189-217.

Kane, M. J., Meier, M. E., Smeekens, B. A., Gross, G. M., Chun, C. A., Silvia, P. J., \& Kwapil, T. R. (2016). Individual differences in the executive control of attention, memory, and thought, and their associations with schizotypy. Journal of Experimental Psychology: General, 145(8), 1017.

Kane, M.J., Smeekens, B.A., von Bastian, C.C., Lurquin, J.H., Carruth, N.P., Miyake, A. (2017). A combined experimental and individual-differences investigation into mind wandering during a video lecture. Journal of Experimental Psychology: General, 146, 1649-1674.

Keyes, K. M., Hatzenbuehler, M. L., \& Hasin, D. S. (2011). Stressful life experiences, alcohol consumption, and alcohol use disorders: The epidemiologic evidence for four main types of stressors. Psychopharmacology, 218(1), 1-17. 
Killingsworth, M. A., \& Gilbert, D. T. (2010). A wandering mind is an unhappy mind. Science, 330(6006), 932-932.

Kleider, H. M., Parrott, D. J., \& King, T. Z. (2010). Shooting behaviour: How working memory and negative emotionality influence police officer shoot decisions. Applied Cognitive Psychology, 24(5), 707-717.

Klein, K., \& Barnes, D. (1994). The relationship of life stress to problem solving: Task complexity and individual differences. Social Cognition, 12(3), 187-204.

Klein, K., \& Boals, A. (2001). The relationship between life event stress and working memory capacity. Applied Cognitive Psychology, 15, 565-579. doi: 10.1002/acp.727

Kliegl, R., Wei, P., Dambacher, M., Yan, M., \& Zhou, X. (2010). Experimental effects and individual differences in linear mixed models: Estimating the relationship between spatial, object, and attraction effects in visual attention. Frontiers in Psychology, 1.

Knowles, D., \& Tay, R. S. (2002). Driver inattention: more risky than the fatal four? Transportation Research Part F: Traffic Psychology and Behaviour.

Kuhlmann, S., Piel, M., \& Wolf, O. T. (2005). Impaired memory retrieval after psychosocial stress in healthy young men. Journal of Neuroscience, 25(11), 2977-2982.

Kuznetsova, A., Brockhoff, P. B., \& Christensen, R. H. B. (2015). Package 'lmerTest'. R package version, 2(0).

Lazarus, R. S., \& Folkman, S. (1984). Stress, appraisal, and coping. Springer publishing company.

Leonard, N. R., Jha, A. P., Casarjian, B., Goolsaran, M., Garcia, C., Cleland, C. M., Gwadz, M. V., \& Massey, Z. (2013). Mindfulness training improves attentional task performance in 
incarcerated youth: A group randomized controlled intervention trial. Frontiers in Psychology, 4(792), 1-12.

Lewis, R. S., Nikolova, A., Chang, D. J., \& Weekes, N. Y. (2008). Examination stress and components of working memory. Stress, 11(2), 108-114.

Luke, S. G. (2017). Evaluating significance in linear mixed-effects models in R. Behavior Research Methods, 49(4), 1494-1502.

Marchetti, I., Koster, E. H., Klinger, E., \& Alloy, L. B. (2016). Spontaneous thought and vulnerability to mood disorders: the dark side of the wandering mind. Clinical Psychological Science, 4(5), 835-857.

McVay, J. C., \& Kane, M. J. (2012). Why does working memory capacity predict variation in reading comprehension? On the influence of mind wandering and executive attention. Journal of Experimental Psychology: General, 141(2), 302.

Meier, M. E., \& Kane, M. J. (2013). Working memory capacity and Stroop interference: Global versus local indices of executive control. Journal of Experimental Psychology: Learning, Memory, and Cognition, 39(3), 748.

Moore, A., \& Malinowski, P. (2009). Meditation, mindfulness and cognitive flexibility. Consciousness and Cognition, 18(1), 176-186.

Mrazek, M. D., Franklin, M. S., Phillips, D. T., Baird, B., \& Schooler, J. W. (2013). Mindfulness training improves working memory capacity and GRE performance while reducing mind wandering. Psychological Science, 24(5), 776-781.

Nolen-Hoeksema, S. (2000). The role of rumination in depressive disorders and mixed anxiety/depressive symptoms. Journal of Abnormal Psychology, 109(3), 504. 
Nolen-Hoeksema, S., \& Morrow, J. (1991). A prospective study of depression and posttraumatic stress symptoms after a natural disaster: the 1989 Loma Prieta Earthquake. Journal of personality and social psychology, 61(1), 115.

Nolen-Hoeksema, S., Wisco, B. E., \& Lyubomirsky, S. (2008). Rethinking rumination. Perspectives on Psychological Science, 3(5), 400-424.

Pechtel, P., \& Pizzagalli, D. A. (2011). Effects of early life stress on cognitive and affective function: an integrated review of human literature. Psychopharmacology, 214(1), 55-70.

Preacher, K. J., \& Hayes, A. F. (2008). Asymptotic and resampling strategies for assessing and comparing indirect effects in multiple mediator models. Behavior Research Methods, 40(3), 879-891.

Psychology Software Tools, Inc. [E-Prime 2.0]. (2012). Retrieved from http://www.pstnet.com.

Qin, S., Hermans, E. J., van Marle, H. J., Luo, J., \& Fernández, G. (2009). Acute psychological stress reduces working memory-related activity in the dorsolateral prefrontal cortex. Biological Psychiatry, 66(1), 25-32.

R Core Team (2017). R: A language and environment for statistical computing. R Foundation for Statistical Computing, Vienna, Austria. URL https://www.R-project.org/.

Rahe, R. H., \& Lind, E. (1971). Psychosocial factors and sudden cardiac death: A pilot study. Journal of Psychosomatic Research, 15(1), 19-24.

Raichle, M. E., MacLeod, A. M., Snyder, A. Z., Powers, W. J., Gusnard, D. A., \& Shulman, G. L. (2001). A default mode of brain function. Proceedings of the National Academy of Sciences, 98(2), 676-682. 
Randall, J. G., Oswald, F. L., \& Beier, M. E. (2014). Mind-wandering, cognition, and performance: A theory-driven meta-analysis of attention regulation. Psychological Bulletin, 140(6), 1411.

Robertson, I. H., Manly, T., Andrade, J., Baddeley, B. T., \& Yiend, J. (1997). Oops!':

performance correlates of everyday attentional failures in traumatic brain injured and normal subjects. Neuropsychologia, 35(6), 747-758.

Sarason, I. G., Johnson, J. H., \& Siegel, J. M. (1978). Assessing the impact of life changes: development of the Life Experiences Survey. Journal of Consulting and Clinical Psychology, 46(5), 932.

Schoofs, D., Preub, D., and Wolf, O.T. (2008). Psychosocial stress induces working memory impairments in an n-back paradigm. Psychoneuroendocrinology, 33(5), 643-653.

Segal, Z. V., Williams, M., \& Teasdale, J. (2018). Mindfulness-based cognitive therapy for depression. Guilford Publications.

Sliwinski, M. J., Smyth, J. M., Hofer, S. M., \& Stawski, R. S. (2006). Intraindividual coupling of daily stress and cognition. Psychology and Aging, 21(3), 545.

Smallwood, J., McSpadden, M., \& Schooler, J. W. (2008). When attention matters: The curious incident of the wandering mind. Memory \& Cognition, 36(6), 1144-1150.

Stoltzfus, E. R., Hasher, L., \& Zacks, R. T. (1996). Working memory and aging: Current status of the inhibitory view. Working Memory and Human Cognition, 66-88.

Treynor, W., Gonzalez, R., \& Nolen-Hoeksema, S. (2003). Rumination reconsidered: A psychometric analysis. Cognitive Therapy and Research, 27(3), 247-259.

Turner, M. L., \& Engle, R. W. (1989). Is working memory capacity task dependent? Journal of Memory and Language, 28(2), 127-154. 
Unsworth, N., Heitz, R. P., Schrock, J. C., \& Engle, R. W. (2005). An automated version of the operation span task. Behavior Research Methods, 37(3), 498-505.

Unsworth, N., Redick, T. S., Heitz, R. P., Broadway, J. M., \& Engle, R. W. (2009). Complex working memory span tasks and higher-order cognition: A latent-variable analysis of the relationship between processing and storage. Memory, 17(6), 635-654.

Wagenmakers, E. J., Verhagen, J., \& Ly, A. (2016). How to quantify the evidence for the absence of a correlation. Behavior Research Methods, 48, 413-426.

Wammes, J. D., Seli, P., Cheyne, J. A., Boucher, P. O., \& Smilek, D. (2016). Mind wandering during lectures II: Relation to academic performance. Scholarship of Teaching and Learning in Psychology, 2(1), 33.

Yee, P. L., Edmondson, B., Santoro, K. E., Begg, A. E., \& Hunter, C. D. (1996). Cognitive effects of life stress and learned helplessness. Anxiety, Stress and Coping, 9(4), 301-319.

Zeidan, F., Johnson, S. K., Diamond, B. J., David, Z., \& Goolkasian, P. (2010). Mindfulness meditation improves cognition: Evidence of brief mental training. Consciousness and Cognition, 19(2), 597-605.

Zhao, X., Lynch Jr, J. G., \& Chen, Q. (2010). Reconsidering Baron and Kenny: Myths and truths about mediation analysis. Journal of Consumer Research, 37(2), 197-206. 


\section{APPENDIX A: OPERATION SPAN (OSPAN) COMPLEX SPAN TASK}

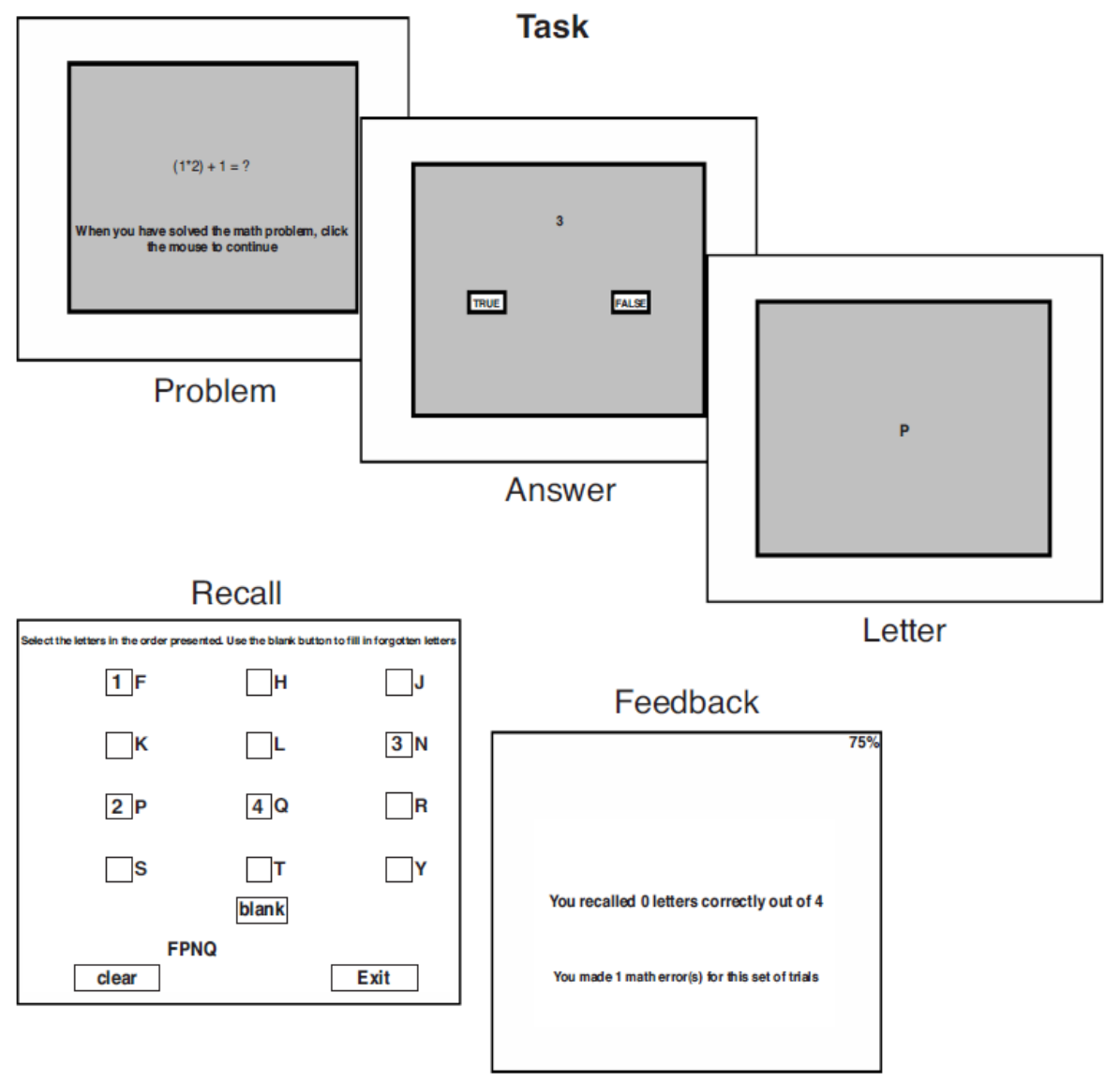




\section{APPENDIX B: SYMMETRY COMPLEX SPAN TASK (SYMSPAN)}

Presentation Phase

\begin{tabular}{|c|c|}
\hline TRIAL & finalTester \\
\hline
\end{tabular}

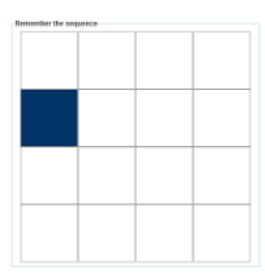

\begin{tabular}{|c|c|}
\hline TRIAL & finalTester \\
\hline
\end{tabular}

\begin{tabular}{|c|c|c|}
\hline & Non-Symmetrical \\
\hline 1 & Symmetrical & User \\
\hline TRIAL & FEEOACK & finalTester \\
\hline
\end{tabular}


Recall phase

\begin{tabular}{|c|c|c|}
\hline TRIAL & finoBACK \\
\hline
\end{tabular}

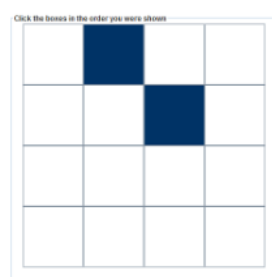




\section{SART assessment}

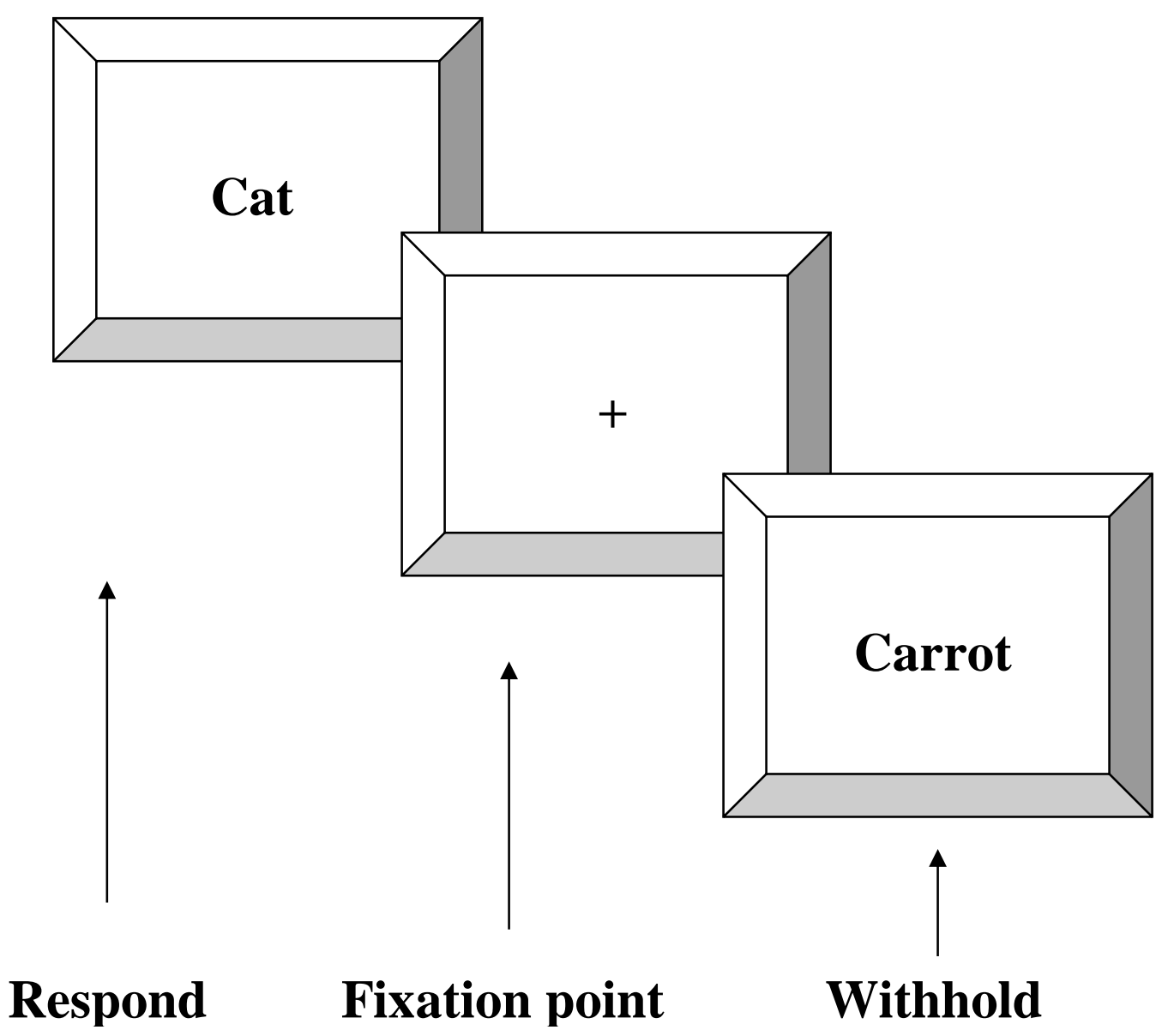




\section{APPENDIX D: THOUGHT PROBES}

Subjects will be presented with the following prompt and response choices during a practice session at the beginning of the SART and during the SART.

Please click on the button to indicate what you were just thinking about:

1. Task-related thoughts, that is, pertaining to the current task

2. Task-related evaluative thoughts - positive

3. Task-related evaluative thoughts - negative

4. Task-unrelated thoughts - neutral content

5. Task-unrelated thoughts - positive content

6. Task-unrelated thoughts - negative content 


\section{APPENDIX E: LIFE EXPERIENCES SURVEY (LES)}

Listed below are a number of events which sometimes bring about change in the lives of those who experience them and which necessitate social readjustment. Please check those events which you have experienced in the recent past, and indicate the time period during which you have experienced each event. Be sure that all checkmarks are directly across from the items they correspond to.

Also, for each item checked below, please indicate the extent to which you view the event as having either a positive or negative impact on your life at the time of the event. That is, indicate the type and extent of impact that the event had on you at that time. A rating of $\mathbf{- 3}$ would indicate an extremely negative impact. A rating of $\mathbf{0}$ suggests no impact either positive or negative. A rating of $+\mathbf{3}$ would indicate an extremely positive impact.
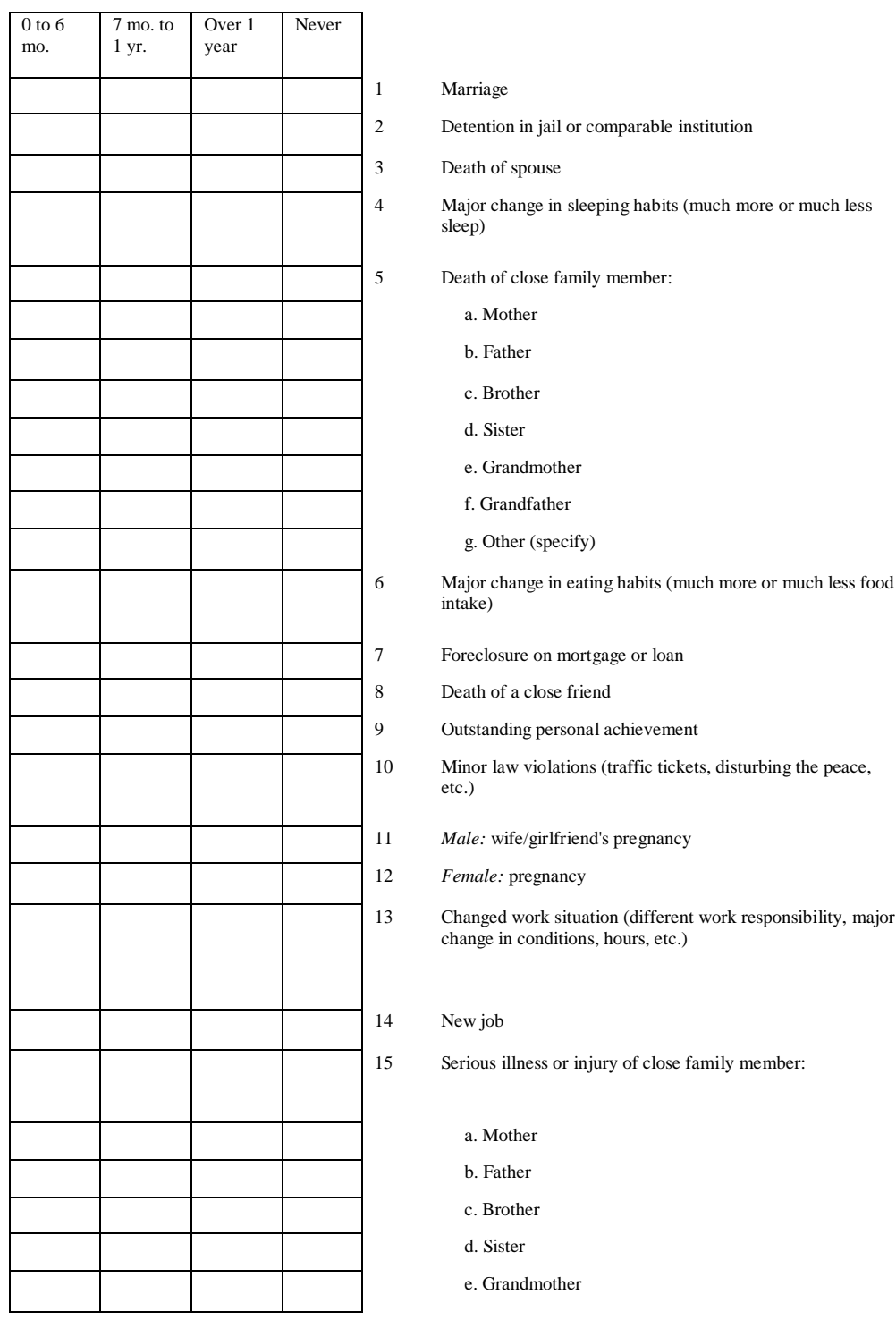

\begin{tabular}{|c|c|c|c|c|c|c|c|}
\hline Neve & & & & & & & \\
\hline $\mathrm{N}$ & -3 & -2 & -1 & 0 & +1 & +2 & +3 \\
\hline $\mathrm{N}$ & -3 & -2 & -1 & 0 & +1 & +2 & +3 \\
\hline $\mathrm{N}$ & -3 & -2 & -1 & 0 & +1 & +2 & +3 \\
\hline $\mathrm{N}$ & -3 & -2 & -1 & 0 & +1 & +2 & +3 \\
\hline $\mathrm{N}$ & -3 & -2 & -1 & 0 & +1 & +2 & +3 \\
\hline $\mathrm{N}$ & -3 & -2 & -1 & 0 & +1 & +2 & +3 \\
\hline $\mathrm{N}$ & -3 & -2 & -1 & 0 & +1 & +2 & +3 \\
\hline $\mathrm{N}$ & -3 & -2 & -1 & 0 & +1 & +2 & +3 \\
\hline $\mathrm{N}$ & -3 & -2 & -1 & 0 & +1 & +2 & +3 \\
\hline $\mathrm{N}$ & -3 & -2 & -1 & 0 & +1 & +2 & +3 \\
\hline $\mathrm{N}$ & -3 & -2 & -1 & 0 & +1 & +2 & +3 \\
\hline $\mathrm{N}$ & -3 & -2 & -1 & 0 & +1 & +2 & +3 \\
\hline $\mathrm{N}$ & -3 & -2 & -1 & 0 & +1 & +2 & +3 \\
\hline $\mathrm{N}$ & -3 & -2 & -1 & 0 & +1 & +2 & +3 \\
\hline $\mathrm{N}$ & -3 & -2 & -1 & 0 & +1 & +2 & +3 \\
\hline $\mathrm{N}$ & -3 & -2 & -1 & 0 & +1 & +2 & +3 \\
\hline $\mathrm{N}$ & -3 & -2 & -1 & 0 & +1 & +2 & +3 \\
\hline $\mathrm{N}$ & -3 & -2 & -1 & 0 & +1 & +2 & +3 \\
\hline $\mathrm{N}$ & -3 & -2 & -1 & 0 & +1 & +2 & +3 \\
\hline $\mathrm{N}$ & -3 & -2 & -1 & 0 & +1 & +2 & +3 \\
\hline $\mathrm{N}$ & -3 & -2 & -1 & 0 & +1 & +2 & +3 \\
\hline $\mathrm{N}$ & -3 & -2 & -1 & 0 & +1 & +2 & +3 \\
\hline $\mathrm{N}$ & -3 & -2 & -1 & 0 & +1 & +2 & +3 \\
\hline $\mathrm{N}$ & -3 & -2 & -1 & 0 & +1 & +2 & +3 \\
\hline $\mathrm{N}$ & -3 & -2 & -1 & 0 & +1 & +2 & +3 \\
\hline $\mathrm{N}$ & -3 & -2 & -1 & 0 & +1 & +2 & +3 \\
\hline $\mathrm{N}$ & -3 & -2 & -1 & 0 & +1 & +2 & \\
\hline
\end{tabular}




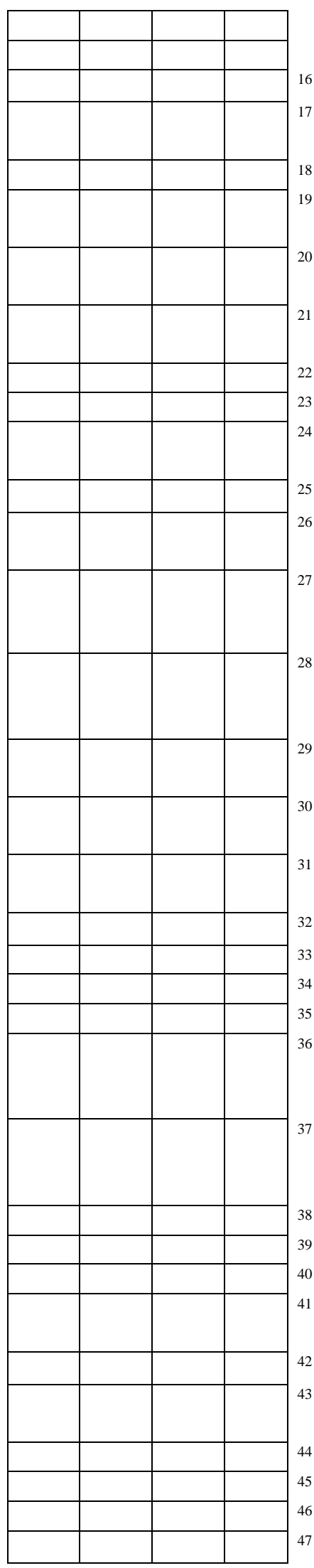

f. Grandfather

g. Other (specify)

Sexual difficulties

Trouble with employer (in danger of losing job, being suspended, demoted, etc.)

Trouble with in-laws

Major change in financial status (a lot better off or a lot worse off)

Major change in closeness of family members (increased or decreased closeness)

Gaining a new family member (through birth, adoption,

family member moving in, etc.)

Change of residence

Marital separation from mate (due to conflict)

Major change in church activities (increased or decreased attendance)

Marital reconciliation with mate

Major change in number of arguments with spouse (a lot more or a lot less arguments)

Married male: Change in wife's work outside the home (beginning work, ceasing work, changing to a new job, etc.)

Married female: Change in husband's work (loss of job, beginning new job, retirement, etc.)

Major change in usual type and/or amount of recreation

Borrowing more than $\$ 10,000$ (buying home, business, etc.)

Borrowing less than $\$ 10,000$ (buying car, TV, getting school loan, etc.)

Being fired from job

Male: Wife/girlfriend having abortion

Female: Having abortion

Major personal illness or injury

Major change in social activities, e.g. parties, movies, visiting (increased / decreased participation)

Major change in living conditions of family (building new home, remodeling, deterioration of home, neighborhood, etc.)

Divorce

Serious injury or illness of close friend

Retirement from work

Son or daughter leaving home (due to marriage, college, etc.)

Ending of formal schooling

Separation from spouse

(due to work, travel, etc.)

Engagement

Breaking up with boyfriend/ girlfriend

Leaving home for the first time

Reconciliation with boyfriend/ girlfriend

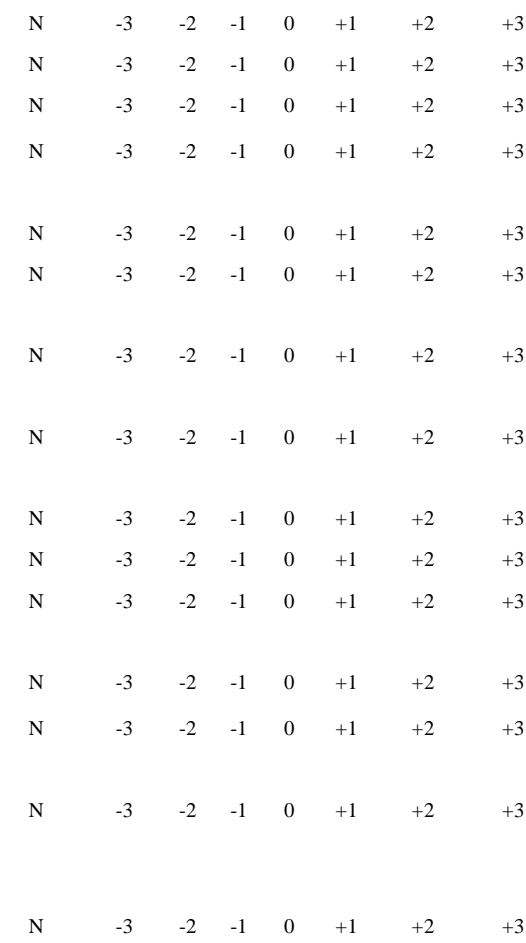

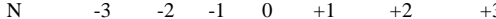

$\begin{array}{llllllll}\mathrm{N} & -3 & -2 & -1 & 0 & +1 & +2 & +3\end{array}$

$\begin{array}{lllllllll}\mathrm{N} & -3 & -2 & -1 & 0 & +1 & +2 & +3\end{array}$

$\begin{array}{lllllllll}\mathrm{N} & -3 & -2 & -1 & 0 & +1 & +2 & +3\end{array}$

$\begin{array}{llllllll}\mathrm{N} & -3 & -2 & -1 & 0 & +1 & +2 & +3\end{array}$

$\begin{array}{llllllll}\mathrm{N} & -3 & -2 & -1 & 0 & +1 & +2 & +3\end{array}$

$\begin{array}{llllllll}\mathrm{N} & -3 & -2 & -1 & 0 & +1 & +2 & +3\end{array}$

$\begin{array}{llllllll}\mathrm{N} & -3 & -2 & -1 & 0 & +1 & +2 & +3\end{array}$

$\begin{array}{lllllllll}\mathrm{N} & -3 & -2 & -1 & 0 & +1 & +2 & +3\end{array}$

$\begin{array}{lllllllll}\mathrm{N} & -3 & -2 & -1 & 0 & +1 & +2 & +3\end{array}$

$\begin{array}{llllllll}\mathrm{N} & -3 & -2 & -1 & 0 & +1 & +2 & +3\end{array}$

$\begin{array}{lllllllll}\mathrm{N} & -3 & -2 & -1 & 0 & +1 & +2 & +3\end{array}$

$\begin{array}{llllllll}\mathrm{N} & -3 & -2 & -1 & 0 & +1 & +2 & +3\end{array}$

$\begin{array}{lllllllll}\mathrm{N} & -3 & -2 & -1 & 0 & +1 & +2 & +3\end{array}$

$\begin{array}{llllllll}\mathrm{N} & -3 & -2 & -1 & 0 & +1 & +2 & +3\end{array}$

$\begin{array}{lllllllll}\mathrm{N} & -3 & -2 & -1 & 0 & +1 & +2 & +3\end{array}$

$\begin{array}{lllllllll}\mathrm{N} & -3 & -2 & -1 & 0 & +1 & +2 & +3\end{array}$

$\begin{array}{llllllll}\mathrm{N} & -3 & -2 & -1 & 0 & +1 & +2 & +3\end{array}$

$\begin{array}{lllllllll}\mathrm{N} & -3 & -2 & -1 & 0 & +1 & +2 & +3\end{array}$ 


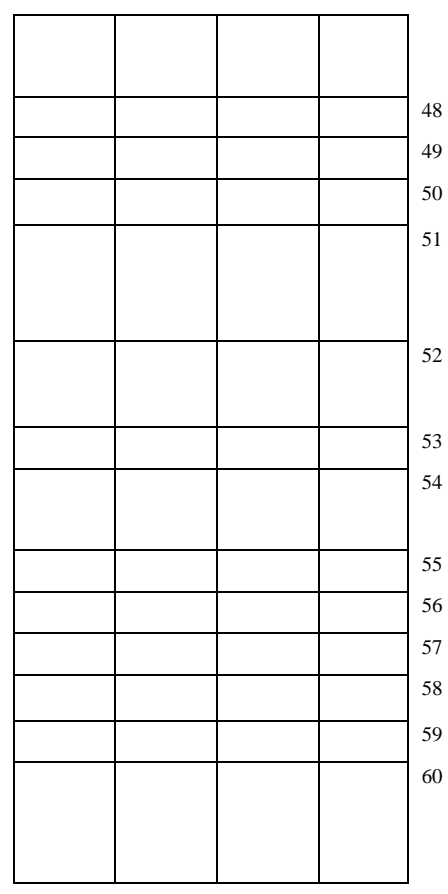

Other recent experiences which have had an impact on your life. List and rate.

$\begin{array}{llllllll}\mathrm{N} & -3 & -2 & -1 & 0 & +1 & +2 & +3 \\ \mathrm{~N} & -3 & -2 & -1 & 0 & +1 & +2 & +3 \\ \mathrm{~N} & -3 & -2 & -1 & 0 & +1 & +2 & +3 \\ \mathrm{~N} & -3 & -2 & -1 & 0 & +1 & +2 & +3 \\ \mathrm{~N} & -3 & -2 & -1 & 0 & +1 & +2 & +3 \\ & & & & & & & \\ & & & & & & & \\ \mathrm{~N} & -3 & -2 & -1 & 0 & +1 & +2 & +3 \\ & & & & & & & \\ \mathrm{~N} & -3 & -2 & -1 & 0 & +1 & +2 & +3 \\ \mathrm{~N} & -3 & -2 & -1 & 0 & +1 & +2 & +3 \\ & & & & & & & \\ \mathrm{~N} & -3 & -2 & -1 & 0 & +1 & +2 & +3 \\ \mathrm{~N} & -3 & -2 & -1 & 0 & +1 & +2 & +3 \\ \mathrm{~N} & -3 & -2 & -1 & 0 & +1 & +2 & +3 \\ \mathrm{~N} & -3 & -2 & -1 & 0 & +1 & +2 & +3 \\ \mathrm{~N} & -3 & -2 & -1 & 0 & +1 & +2 & +3 \\ \mathrm{~N} & -3 & -2 & -1 & 0 & +1 & +2 & +3\end{array}$

Example of computerized task:

Have and when did you experience:

Detention in jail or comparable institution

1. Never

2. 0-6 months ago

3. 7-12 months ago

4. Over 1 year ago 
Indicate the extent to which you view the event as having either a

positive or negative impact on your life:

Detention in jail or comparable institution

1. -3

2. -2

3. -1

4. 0

5. +1

6. +2

7. +3

8. Never experienced 


\section{APPENDIX F: RUMINATIVE RESPONSE SCALE}

People think and do many different things when they feel depressed. Please read each of the items below and indicate whether you almost never, sometimes, often, or almost always think or do each one when you feel down, sad, or depressed. Please indicate what you generally do, not what you think you should do.

1 almost never 2 sometimes 3 often 4 almost always

1. think about how alone you feel

2. think "I won't be able to do my job if I don't snap out of this"

3. think about your feelings of fatigue and achiness

4. think about how hard it is to concentrate

5. think "What am I doing to deserve this?"

6. think about how passive and unmotivated you feel.

7. analyze recent events to try to understand why you are depressed

8. think about how you don't seem to feel anything anymore

9. think "Why can't I get going?"

10. think "Why do I always react this way?"

11. go away by yourself and think about why you feel this way

12. write down what you are thinking about and analyze it

13. think about a recent situation, wishing it had gone better

14. think "I won't be able to concentrate if I keep feeling this way."

15. think "Why do I have problems other people don't have?"

16. think "Why can't I handle things better?"

17. think about how sad you feel.

18. think about all your shortcomings, failings, faults, mistakes

19. think about how you don't feel up to doing anything

20. analyze your personality to try to understand why you are depressed

21.go someplace alone to think about your feelings

22. think about how angry you are with yourself 


\section{APPENDIX G: FIVE FACET MINDFULNESS QUESTIONNAIRE - SHORT FORM}

Below is a collection of statements about your everyday experience. Using the 1-5 scale below, please indicate, in the box to the right of each statement, how frequently or infrequently you have had each experience in the last month (or other agreed time period). Please answer according to what really reflects your experience rather than what you think your experience should be.

Never or Very Rarely True -1

Not often true -2

Some true/ sometimes not true -3

Often true - 4

Very often or always true -5

1 I'm good at finding the words to describe my feelings

2 I can easily put my beliefs, opinions, and expectations into words

3 I watch my feelings without getting carried away by them

$4 \quad$ I tell myself that I shouldn't be feeling the way I'm feeling

$5 \quad$ it's hard for me to find the words to describe what I'm thinking

6 I pay attention to physical experiences, such as the wind in my hair or sun on my face

7 I make judgments about whether my thoughts are good or bad.

8 I find it difficult to stay focused on what's happening in the present moment

9 when I have distressing thoughts or images, I don't let myself be carried away by them

10 generally, I pay attention to sounds, such as clocks ticking, birds chirping, or cars passing

11 when I feel something in my body, it's hard for me to find the right words to describe it

12 it seems I am "running on automatic" without much awareness of what I'm doing

13 when I have distressing thoughts or images, I feel calm soon after

14 I tell myself I shouldn't be thinking the way I'm thinking 
15 I notice the smells and aromas of things

16 even when I'm feeling terribly upset, I can find a way to put it into words

17 I rush through activities without being really attentive to them

18 usually when I have distressing thoughts or images I can just notice them without reacting

19 I think some of my emotions are bad or inappropriate and I shouldn't feel them

20 I notice visual elements in art or nature, such as colors, shapes, textures, or patterns of light and shadow

21 when I have distressing thoughts or images, I just notice them and let them go

22 I do jobs or tasks automatically without being aware of what I'm doing

23 I find myself doing things without paying attention

24 I disapprove of myself when I have illogical ideas 